\title{
Research Paper \\ Application of structural equation model in explaining the role of cognitive flexibility, emotional self-regulation and actively open-minded thinking on changing people's attitudes
}

\begin{abstract}
Citation: Chellemal DezfooliNejad E, Momeni F, Pedram M.M, Mordi A. Application of structural equation model in explaining the role of cognitive flexibility, emotional self-regulation and actively openminded thinking on changing people's attitudes. J of Psychological Science. 2021; 20(106): 1831-1847.
\end{abstract}

Ebrahim Chellemal DezfooliNejad ${ }^{1}$, Farzan Momeni ${ }^{2}$, MirMohsen Pedram ${ }^{3}$, Alireza Mordi ${ }^{4}$

1. Ph.D Student in Cognitive Modeling, Department of Cognitive Modeling, Institute for Cognitive Science Studies, Tehran, Iran.

2. Assistant Professor, Department of Physics, Kharazmi University, Tehran, Iran (Adjunct Professor of the Institute for Cognitive Science Studies ,Tehran, Iran).

3. Associate Professor, Department of Computer Engineering, Facuty of Engineering, Kharazmi University,Tehran, Iran.

4. Professor, Department of Clinical Psychology, Faculty of Psychology and Education, Kharazmi University, Tehran, Iran.

URL: https://psychologicalscience.ir/article-1-1348-fa.html
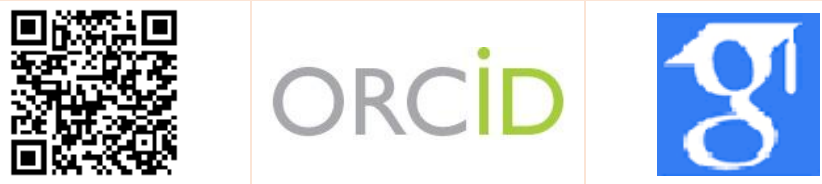

\section{A R T I C L E I N F O}

\section{Keywords:}

Attitude,

Social networks,

Emotional

regulation,

Cognitive flexibility,

Actively open-minded

thinking

Received: 26 Jul 2021

Accepted: 21 Aug 2021

Available: 22 Dec 2021

\section{A B S T R A C T}

Background: Due to the growing trend of social networks and the expansion of their impact, studies have been conducted on the impact of these networks on attitudes, behaviors and lifestyles, etc. However, no study has been done on the effect of cognitive indicators on attitude change in social networks.

Aims: The purpose of this study is to present a conceptual model to examine the effect of three factors: (1) cognitive flexibility, (2) emotional self-regulation, and (3) actively open-minded thinking on changing people's attitudes in social networks.

Methods: The method of the present study is descriptive.Data collection was done via survey method. The statistical population includes all users of social networks. The statistical sample included 384 men and women who were selected by convenience sampling. To examine the effect of cognitive flexibility, emotional self-regulation, and actively open minded thinking on attitude change, following three scales were used respectively, Martin and Rubin Cognitive Flexibility Scale (Martin and Rubin, 1995), Emotional Self-Regulation Questionnaire (Hoffman, \& Kashdan, 2010), Actively Open-Minded Thinking Questionnaire (Stanovich \&West 2007). The attitudes of individuals was examined by researcher-made questionnaires whose content validity was confirmed by experts and their reliability was confirmed by statistical methods. After confirming the normality of the data, structural equation modeling with lisrel software was used.

Results: Testing the hypotheses performed by structural equations showed that mentioned indicators have an acceptable $t$ value at a significant level $(\mathrm{p}<0.05)$. Therefore, they are effective in changing people's attitudes. Emotional self-regulation was also shown to have the greatest effect $(0.9)$ on changing attitudes toward domestic violence.

Conclusion: This means that the cognitive abilities of social network users have a direct impact on changing their attitudes.

* Corresponding Author: Farzan Momeni, Assistant Professor, Department of Physics, Kharazmi University, Tehran, Iran (Adjunct Professor of the Institute for Cognitive Science Studies ,Tehran, Iran)

E-mail: momeni@khu.ac.ir

Tel: (+98) 9125033874

2476-5740/ (C) 2021 The Authors. This is an open access article under the CC BY-NC-ND license

(https://creativecommons.org/licenses/by-nc/4.0/). 


\section{Extended Abstract}

\section{Introduction}

Social media are becoming an increasingly important part of many people's lives and our society.The timeline provided by Facebook states that in the first three months of 2021, about 3.45 billion people used at least one of the company's main products (Instagram, WhatsApp, etc.). This is changing the way people communicate, how they acquire information, and how they form beliefs (Schwartz, 2017). The abundance of information on social networks quickly provides acceptable patterns for individuals and can therefore improve the cultural conditions of society by filling gaps, developing culture, and promoting a positive view of law, as well as fostering a morally correct stance on important social and cultural issues. Therefore, the methods and reasons by which the attitudes of social media users is formed is very important. The topic is covered in this article. The process by which the opinions of social media users are shaped and changed on the two following issues was examined; (1) domestic violence (2) traffic laws.These served as two important issues of this study. Considering that cognitive abilities and individual characteristics are effective factors in how to use social networks (Emami Rizi, 2016), in this study, the effect of three psychological indicators including cognitive flexibility, emotional self-regulation and actively open minded thinking on social network users' attitudes was explored. Studies have been conducted in relation to the effects of using social networks on behavior, attitude, habits, thinking styles, studies (Boor Boor and Tajik, 2021; Eydi Zade \&Ahmadi Blotaki, 2018; Forghani\&Mohajeri, 2018; Shekari Namin \&Hajiani, 2014; Baqaei et al., 2011).Due to the fact that no direct study has been done on the effect of cognitive indicators on attitude change in social networks, this is considered as the main goal of this study. In order to evaluate the concerns of the present study, the relationship between the considered variables was considered as structural equation modeling and the extent and nature of the effect of these indicators was measured.

\section{Method}

The method of this study is descriptive.Data collection was done via survey method.According to the research limitation and opinions of experts and Morgan table, a total of 384 people (men and women) active in different groups of social networks were considered as an available sample.Insruments: The Martin and Rubin Cognitive Flexibility Scale was used to assess cognitive flexibility. To assess cognitive self-regulation, the emotional selfregulation questionnaire was used(Hoffman and Kashedan, 2010).The Actively Open Minded Thinking Questionnaire was used to assess meta cognitive tendencies (Stanovich \& West, 2007). Standard questionnaires were used to comprehensively examine people's attitudes toward domestic violence and traffic laws, instead of using a single binary question indicating of agreeing or disagreeing. Sample individuals were invited to participate in the study through a formal online invitation. Before starting the group activity, individuals 'scores were measured in three indicators: cognitive flexibility, emotional self-regulation, and actively open minded thinking, as well as individuals' attitudes toward domestic violence and traffic laws. After measuring psychological indicators, the group discussion was started. The participants had a chance to communicate their ideas and opinion on various topics, including the two main topics of this research, in several sessions. At the end of the discussion, people's attitudes toward domestic violence and traffic laws were re-evaluated by the initial tests mentioned. The reliability and validity of the questionnaires were checked and the normality of the data was assessed using Kolmogorov- Smirnov test. Structural equation modeling test and LISREL software were used to examine the research hypotheses.

\section{Results}

The research hypotheses were tested using structural equation modeling which are shown in the following diagram. Figure (1) shows the structural equation model of the research in the case of estimating standard coefficients. 


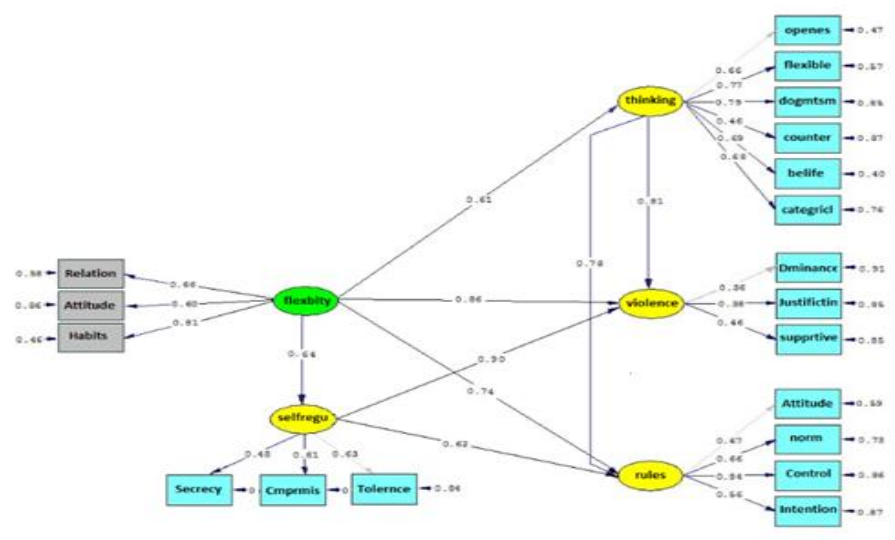

Figure 1. Measuring the general model and the results of the hypotheses in the standard mode

Figure (2) shows the structural equation model of the research in the significant state of $\mathrm{T}$ and Liu coefficients. The calculated values of $t$ for each of the factor loads of each indicator with its hidden structure or variable are above 1.96. Therefore, the alignment of the questionnaire questions to measure the concepts can be considered valid at this stage.

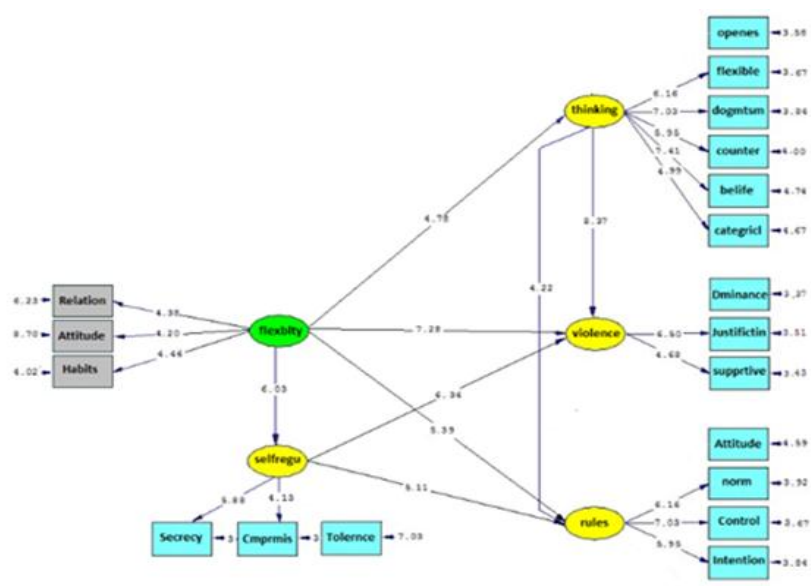

Figure 2. Assessing the general model and the results of the hypotheses in a significant way

Another type of relationship between latent variables in the structural equation model is direct effect.The results of this method are stated in Table 1.

Table 1. Path coefficients, t-statistic and the result of research hypotheses

\begin{tabular}{|c|c|c|c|c|c|}
\hline hypotheses & $\begin{array}{l}\text { Path coefficient } \\
\qquad(\beta)\end{array}$ & $\begin{array}{l}\text { The coefficient } \\
\text { of determination }\end{array}$ & $t$-statistic & $\begin{array}{l}\text { Significant } \\
\text { level }\end{array}$ & $\begin{array}{l}\text { The result of the } \\
\text { researcher } \\
\text { hypothesis }\end{array}$ \\
\hline $\begin{array}{l}\text { 1.Cognitive flexibility has a significant effect on changing } \\
\text { attitudes toward domestic violence against women }\end{array}$ & $0 / 86$ & & $7 / 28$ & $<0.05$ & Approved \\
\hline $\begin{array}{l}\text { 2.Actively open minded thinking has a significant effect on } \\
\text { changing attitudes toward domestic violence against } \\
\text { women. }\end{array}$ & $0 / 81$ & & $8 / 37$ & $<0.05$ & Approved \\
\hline $\begin{array}{l}\text { 3.Emotional self-regulation has a significant effect on } \\
\text { changing attitudes toward domestic violence against } \\
\text { women }\end{array}$ & $0 / 90$ & & $6 / 43$ & $<0.05$ & Approved \\
\hline $\begin{array}{l}\text { 4.Cognitive flexibility has a significant effect on changing } \\
\text { attitudes toward traffic rules. }\end{array}$ & $0 / 74$ & 0.897 & $5 / 39$ & $<0.05$ & Approved \\
\hline $\begin{array}{l}\text { 5.Actively open minded thinking has a significant effect on } \\
\text { changing attitudes toward traffic laws. }\end{array}$ & $0 / 78$ & & $4 / 22$ & $<0.05$ & Approved \\
\hline $\begin{array}{l}\text { 6.Emotional self-regulation has a significant effect on } \\
\text { changing attitudes toward traffic rules }\end{array}$ & $0 / 62$ & & $5 / 11$ & $<0.05$ & Approved \\
\hline $\begin{array}{l}\text { 7.Cognitive flexibility has a significant effect on emotional } \\
\text { self-regulation. }\end{array}$ & $0 / 64$ & & $6 / 03$ & $<0.05$ & Approved \\
\hline $\begin{array}{l}\text { 8.Cognitive flexibility has a significant effect on active } \\
\text { open-minded thinking. }\end{array}$ & $0 / 61$ & & $4 / 78$ & $<0.05$ & Approved \\
\hline
\end{tabular}

\section{Conclusion}

Although the effects of using social networks on behavior, attitude, etc., have been documented in considerable studies, relatively little research is available on the effect of personal characteristics on changing attitudes in social networks. In
Shahamatinejad's study entitled The Relationship between Health Anxiety and Emotion Regulation with Rumors on social networks at the Time of Covid-19, it was shown that there is a significant relationship between cognitive emotion regulation and gossip dissemination on social networks. Social 
network users have caused users to experience cognitive biases (Shahamatinejad, 2021).Shabahang (2019) evaluated the role of cognitive flexibility and emotional regulation problems in students' attitudes toward celebrities and their worship. According to his results, cognitive inflexibility and difficulty in regulating emotions significantly predict the worship of celebrities.

The findings of this study, in line with the research background, showed that emotional self-regulation and cognitive flexibility were effective in changing people's attitudes. Based on the results of this study, more people changed their opinions in regards to domestic violence $(0.9)$ than they did regarding traffic laws (0.62). Perhaps this difference can be explained by the fact that emotion has a two-way interaction with cognition, so that emotional stimuli affect a wide range of cognition-related processes and also the ability of individuals to use cognitive processes is effective in regulating emotion (Ray \& Zald, 2012). Thus, attitudes toward domestic violence, which is a highly emotional issue, are more likely to change. Another variable which was assumed to have an effect on changing people's attitudes is actively openminded thinking. Actively open-minded thinking is closely related to analytical thinking, which includes existing tendencies to examine evidence contrary to one's point of view (Stanovich \& West 2007). Bronstein et al. (2018) found that the scale of users' active intellectual thinking was positively correlated with their ability to distinguish "fake news" titles from real ones. Researchers in another study showed that people with high levels of cognition reduce bias in their judgments by gathering as much information as possible and also thinking about the validity of their thoughts. Therefore, actively open-minded thinking can mediate the need for knowledge and decision-making skills (Jokar and Rahimi, 2013). According to the findings of this study, in line with the above research, actively open-minded thinking has a direct and positive relationship with changing people's opinions. From the results of the present study, it can be seen the extent to which social networks can be effective in spreading people's attitudes. Therefore, it is suggested, to try to identify, control, and prevent social harms and adverse effects of social networks with the structures of cognitive flexibility, emotional self-regulation, and actively open-minded thinking (and possibly other important psychological indicators). Therefore, it is suggested that in order to prevent social harms and adverse effects of social networks, further studies be conducted to identify the cognitive factors affecting the formation of attitudes of social network users.

\section{Ethical Considerations}

Compliance with ethical guidelines: This article is taken from a part of the first author's doctoral dissertation in the field of cognitive modeling at the Institute for Cognitive Science Studies. Participants consciously and voluntarily participated in the research; also the topics were discussed in ethical and legal frameworks and all participants adhered to the research frameworks.

Funding: This study was conducted as a $\mathrm{PhD}$ thesis with no financial support.

Authors' contribution: The first author was the senior author, the second and the third were the supervisors and forth was the advisors.

Conflict of interest: The authors declare no conflict of interest for this study.

Acknowledgments: We would like to thank the supervisors and consultants of this research as well as the participants of the research for being members of the virtual research group in WhatsApp Messenger. 


\title{
كاربرد مدل معادلات ساختارى درتبيين نقش انعطاف يذيرى شناختى، خودنظمجويى هيجان و تفكر فعال روشنفكر انه بر تغييرنترش افراد در شبكه هاى اجتماعى ادئ
}

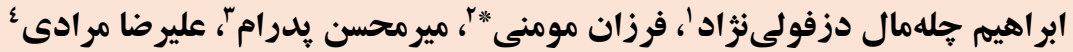

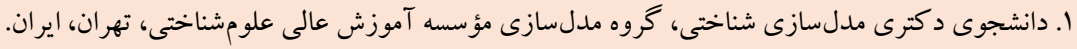

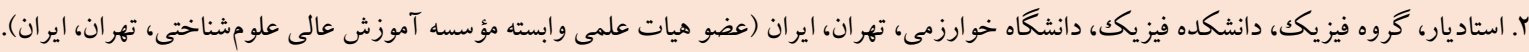

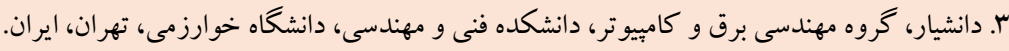

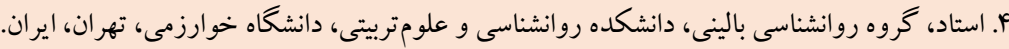

\begin{tabular}{|c|c|}
\hline جكيده & 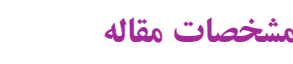 \\
\hline زمينه: با توجه به روند رو به رشد شبكههاى اجتماعى مطالعاتى درمورد تأثير اين شبكها بر روى نخرش، رفتار و سبك زندگى و... انجام & كليدوازهها: \\
\hline شده است. ولى درار تباط با تأثير شاخصهاى شناختى بر روى تغيير نخرش در شبكههاى اجتماعى مطالعه انجام نشده است. & انعطاف يذيرى شناختى، \\
\hline هدف: هدف از اين مطالعه ارائه مدلى مفهومى براى بررسى تأثير عوامل شناختى بر تغيير نخرش افراد در شبكههاى اجتماعى است. در همين & 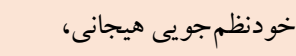 \\
\hline راستا سه عاملٍ (1) انعطاف يذيرى شناختى، (Y) خودنظمجويى هيجانى و (r) تفكر فعال روشنفكرانه به عنوان عوامل شاخص تأثير كذار در & تفكر فعال روشنفكرانه، ت \\
\hline 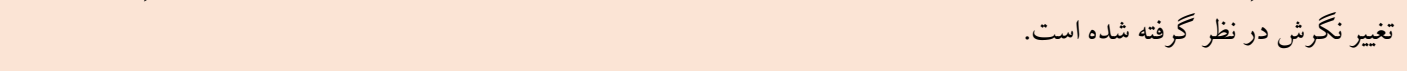 & شبكه ا. \\
\hline \multicolumn{2}{|l|}{ روش: روش تحقيق حاضر به لحاظ ماهيت و شيوه اجرا توصيفى و بيمايشى است. جامعه آمارى شامل تمام كاربران شبكههاى اجتماعى } \\
\hline \multicolumn{2}{|l|}{ است. نمونه آمارى شامل FAF نفر مرد و زن است كه بصورت در دسترس انتخاب شدند. براى بررسى ميزان تأثير هر يكى از اين عوامل } \\
\hline \multicolumn{2}{|l|}{ سه كانهى انعطافيذيرى شناختى، خودنظمجويى هيجان، و تفكر فعال روشنفكرانه، به ترتيب، از مقياس انعطافيذيرى شناختى مارتين و } \\
\hline \multicolumn{2}{|l|}{ 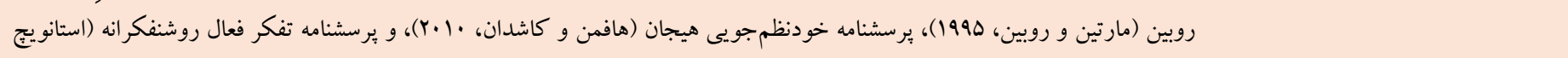 } \\
\hline \multicolumn{2}{|l|}{ 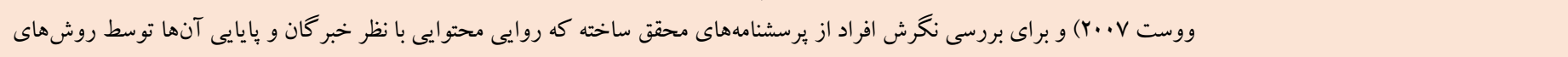 } \\
\hline \multicolumn{2}{|l|}{ آمارى تأييدگرديد؛ استفاده شده است. بِ از تأييد نرمال بودن دادهها از مدلسازى معادلات ساختارى با نرمافزار lisrel استفاده شده است. } \\
\hline \multicolumn{2}{|l|}{ يافته ها: نتايج آزمون فرضيهها با استفاده از مدل سازى معادلات ساختارى نشان داد كه شاخصهاى ذكر شده داراى مقدار t قابل قبول در } \\
\hline \multirow{2}{*}{ 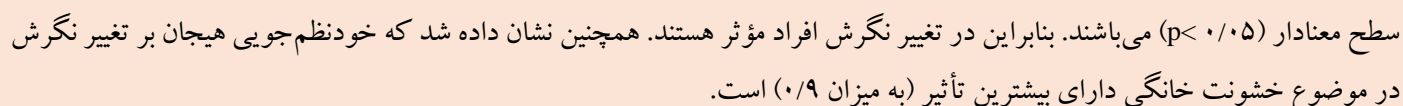 } & 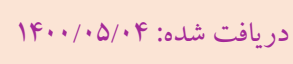 \\
\hline & 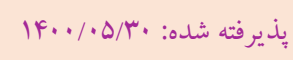 \\
\hline نتيجه كيرى: اين بدان معنى است كه توانايىهاى شناختى كاربران شبكههاى اجتماعى در تغيير نخرشهاى آنها تأثير مستقيم دارد. & 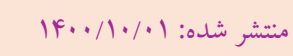 \\
\hline
\end{tabular}

* نويسنده مسئول: فرزان مومنى، استاديار، گروه فيزيك، دانشكده فيزيك، دانشكاه خوارزمى، تهران، ايران (عضو هيات علمى وابسته مؤسسه آموزش عالى علومشناختى، تهران، 
خشونت، به عنوان يك بديدهى نامطلوب اجتماعى، روانى، امنيتى، و

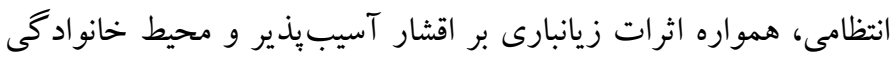

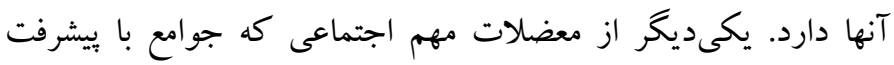

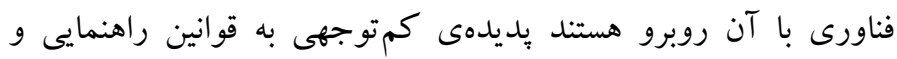

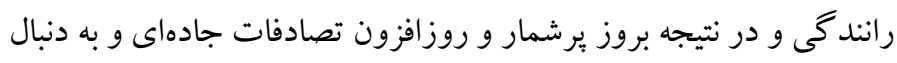

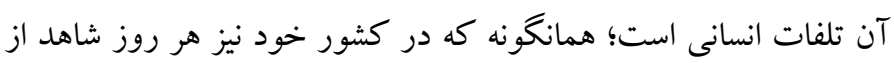

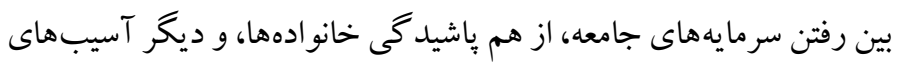

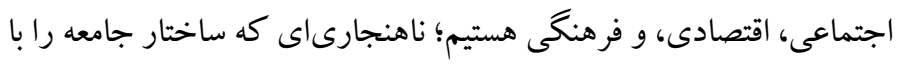

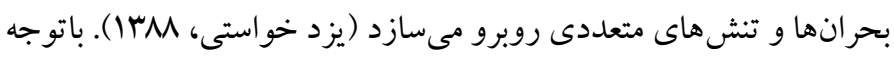

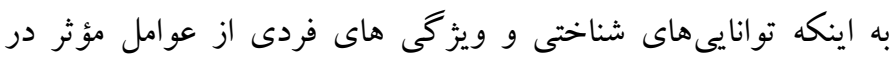

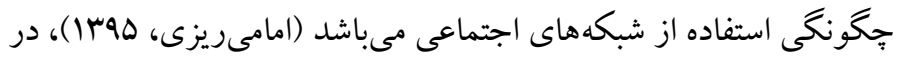

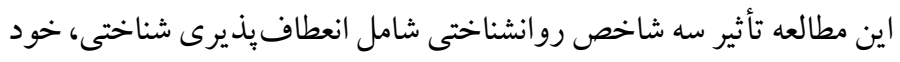

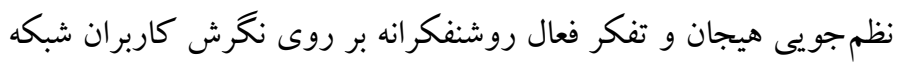

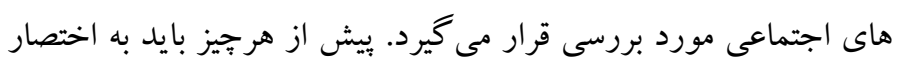

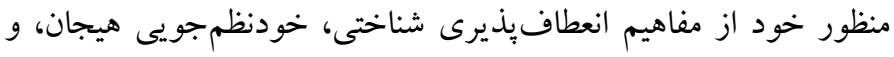

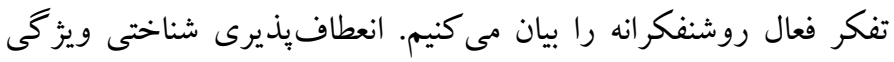
مهمى است كه به انسان كمكك مى كند تا بتواند وظايفى بيّجيده، مانند

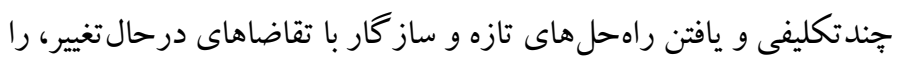

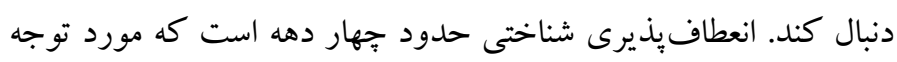

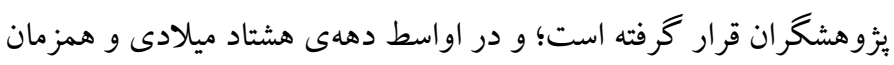

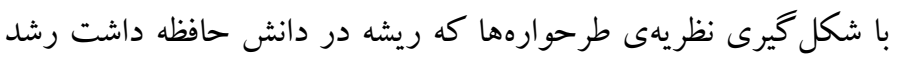
كرد (استد و همكاران، 1) (Y). ظهور انعطاف يذيرى شناختى وابسته به دو نوع تعامل است: تعامل ميان مكانيسمهاى شناختى متعدد، و نيز ميان

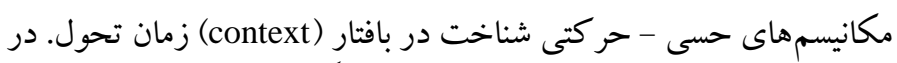

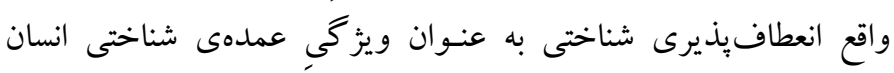
توصيف شده است و به توانايى فرد براى در نظر كرفتن همزمان

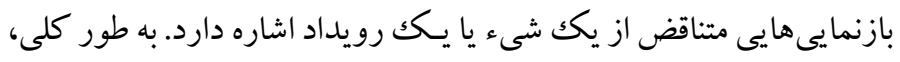
عنصر اصلى در تعاريف عملياتى انعطافيذيرى شناختى؛ توانيى تغيير

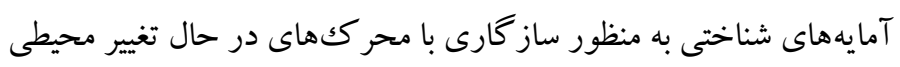

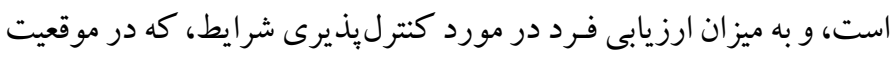

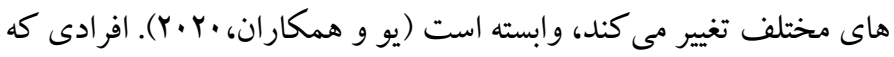

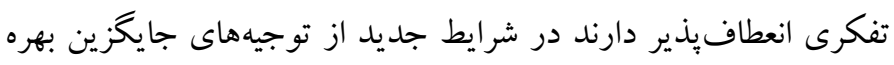

مقام از ميان انواع روشها و فنون مؤثر بر رفتار و نكخرش انسانى، رسانهاى جمعى و شبكه هاى اجتماعى به ويزه وسايل ارتباطى الكترونيكى - به عنوان

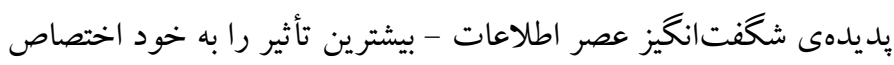

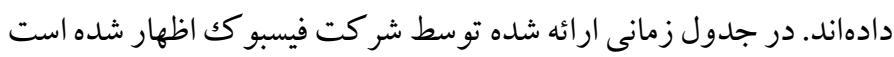

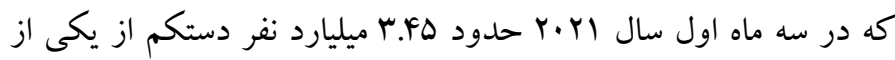
محصو لات اصلى اين شركت (اينستا گرام، واتس آب و....) استفاده كردهاند.

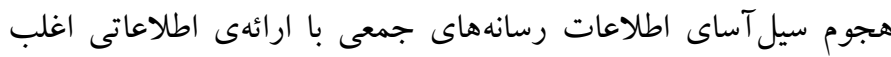

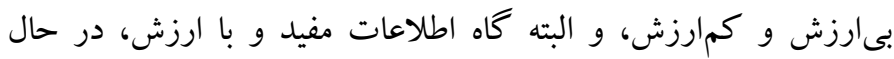

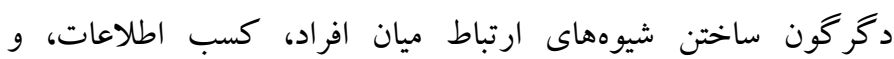

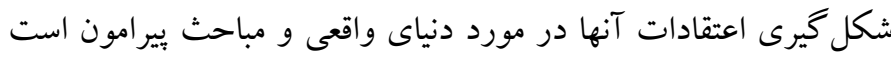

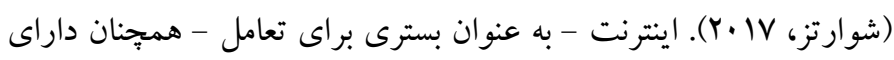

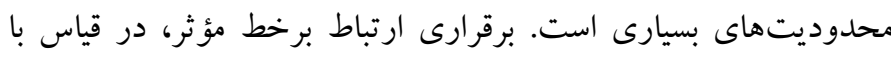

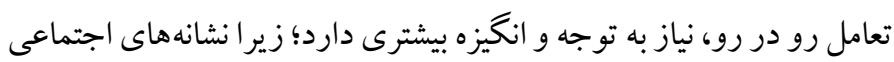

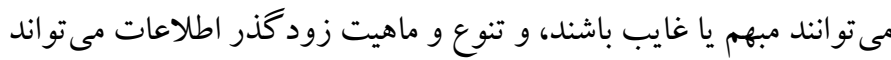

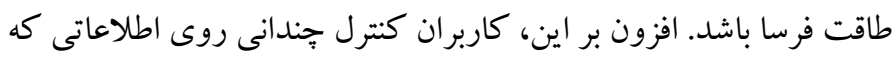

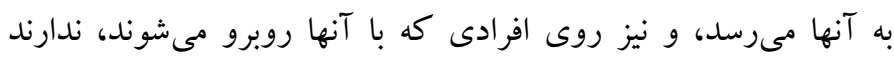

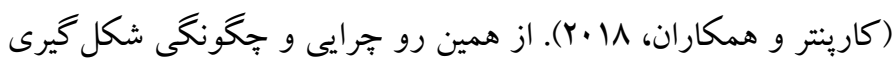

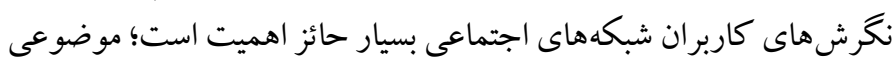

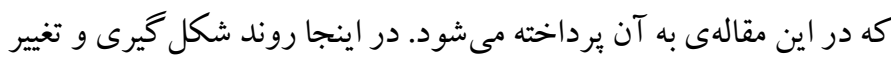

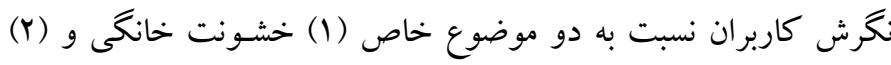
يايبندى به قوانين راهنمايى راند گُى را به عنوان دو نمونهى مهم از مسائل

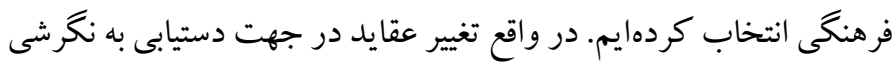

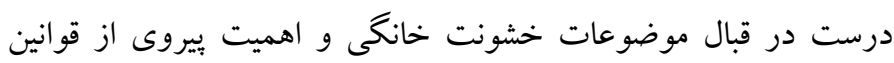

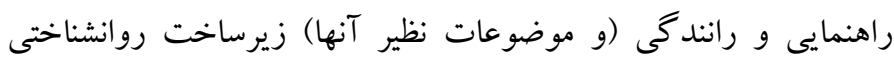

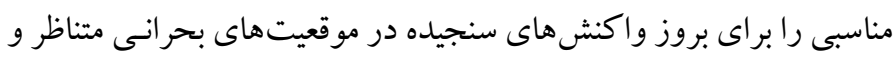
كاستن از ييامدهاى منفى واكنشهاى آنى و ناسنجيده در سطح جامعهد

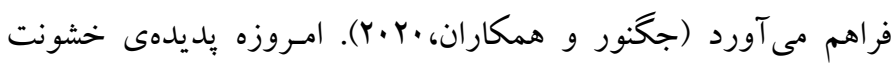

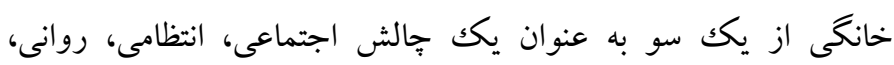

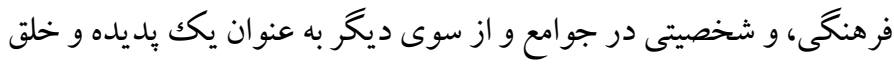

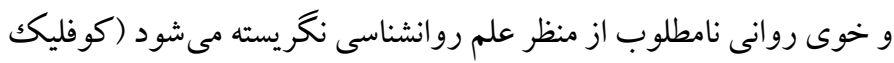

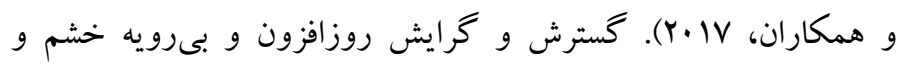


مناسبى براى توجيه رفتار است. همانكونه كه رشدِ توانيىهاى فراشناختى

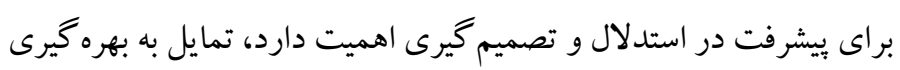

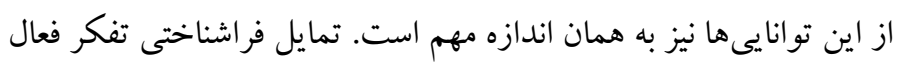

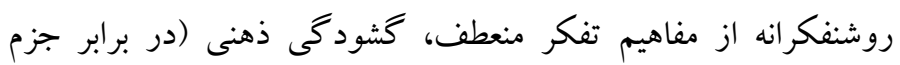

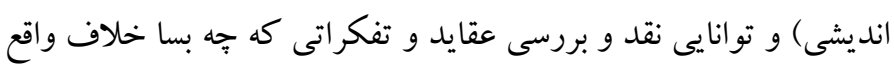

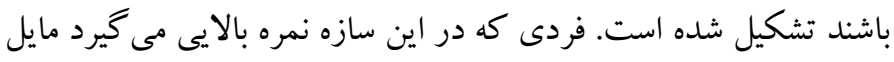
به بررسى فرضيههاى گوناگون است. وى نسبت به تجارب و و ايدهونهاى

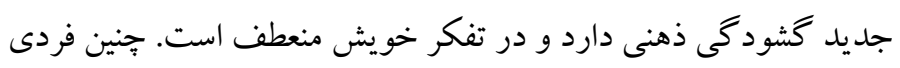

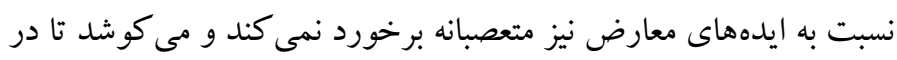
رويارويى با آنها رويكردى منطقى اتخاذ كند. تفكر فعال روشنفكرانه

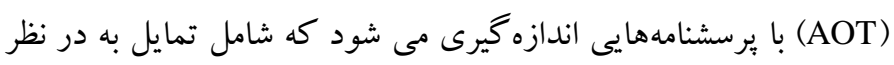
كرفتن نظرات جايخزين، حساسيت به شواهد متناقض با باورهاى فعلى و

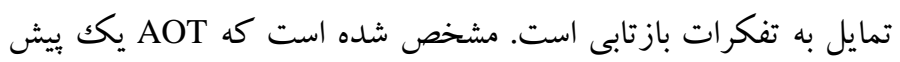

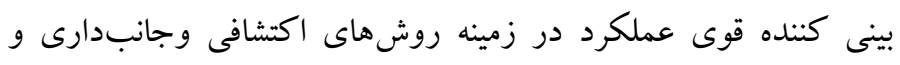
اجتناب از تله هاى استدلال مانند تفكر خر افى و اعتقاد به نظريه توطئه است.

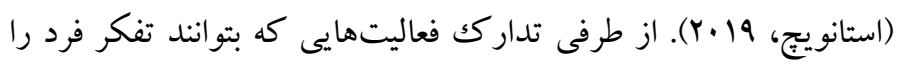
فعالانه به سمت تفكر روشنفكرانه جهتدهى كنند مىتواند در اتخاذ تصميمهاى انطباقى و تحليلىتر و تغيير نخرش صحيح يارىرسان باشد.

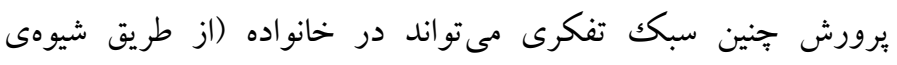

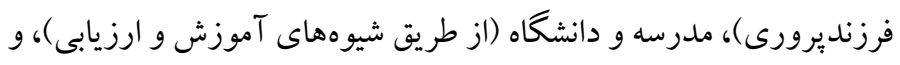
جامعه و فرهنگك (از طريق شبكههاى اجتماعى، ارتباطات و قورونه وانين)،

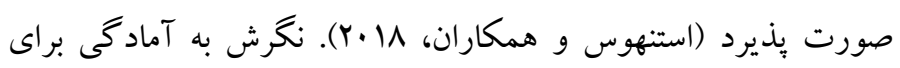
واكنش ويزه نسبت به يك فرد، شىء، فكر، يا موقعيت اطلاق مىشود. از

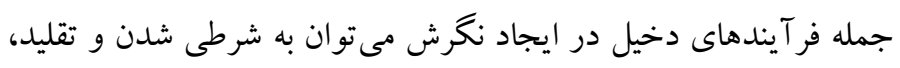

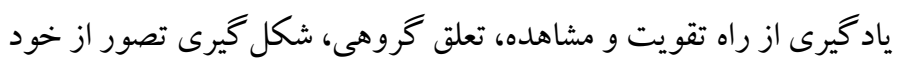

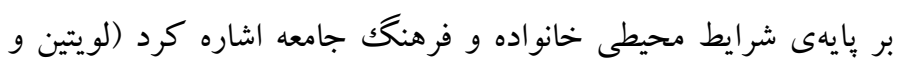

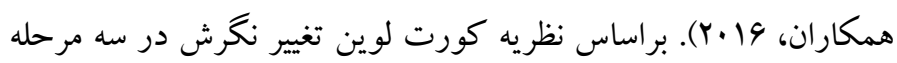

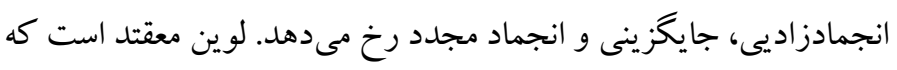

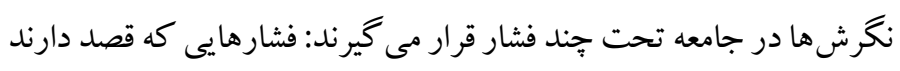
آن را تغيير دهند و فشارهاى ديخر كه قصد دارند آن را محكم تر تحن نمايد. براساس اين نظريه اكر تغيير نخرش جديد به درستى انجام نشود. احتمال

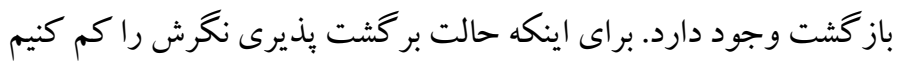

مى گيرند، جارجوب فكرى خود را به شكلى مثبت بازسازى مى كنند،

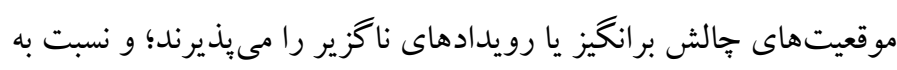

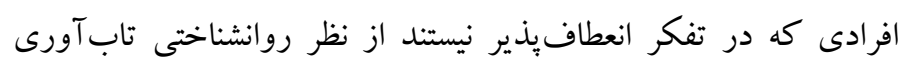

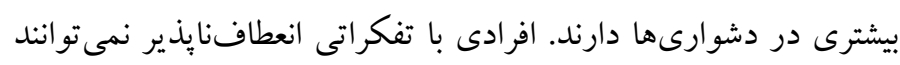

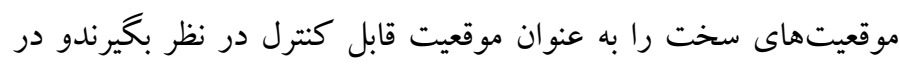

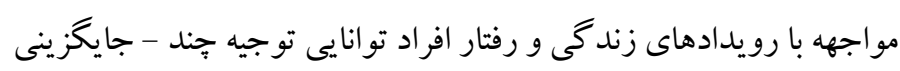

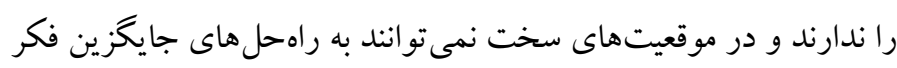

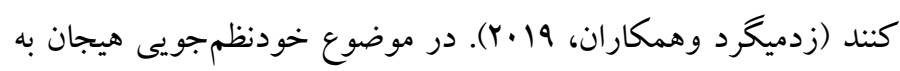
نقش خود آكاهانهى فرد در جريان تنظيم هيجاناتش توجه مى ودود؛ و منظور از تنظيم هيجانات عبارت است از نظارت، ارزيابى و اصلاح تمامى

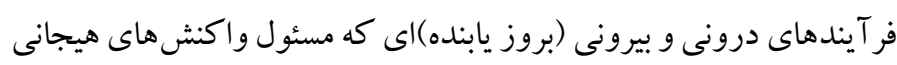
وى، به ويزه حالتهاى حاد و كذرايش هستند، ضمن آنكه اين نظارت،

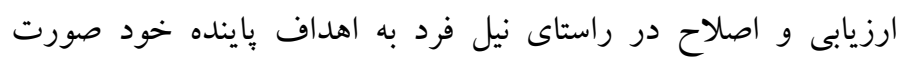

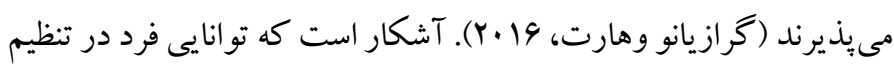

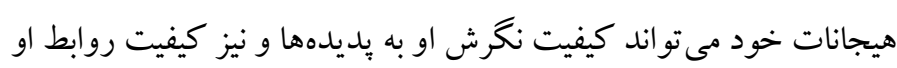

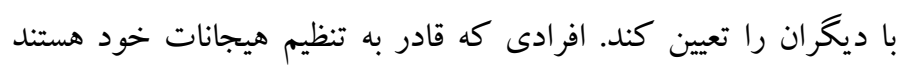

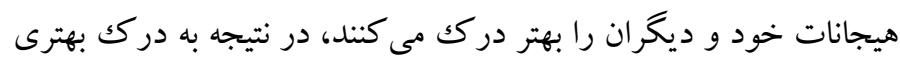

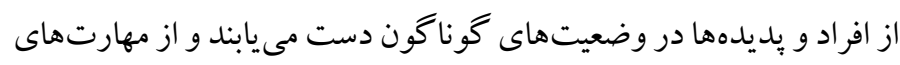
بين فردى و درون فردى توسعه يافته ترى بهرهمند خو اهند بود. بنابر اين جنين

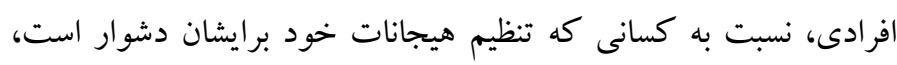

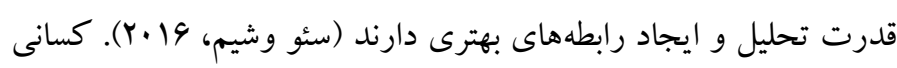
كه در تنظيم هيجانات خود دجار مشكل هستند در بازيابى مجدد موقعيت

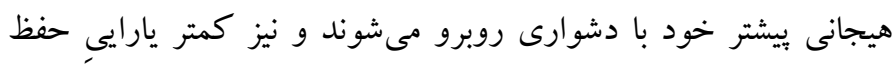

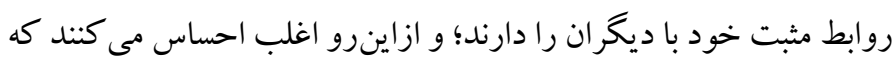

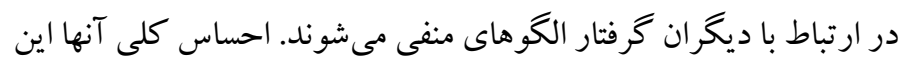

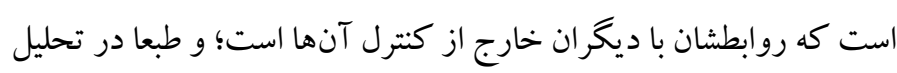
شر ايط، اخذ تصميمهاى درست و نيز تغيير افكار و باورهاى خود و ديخران

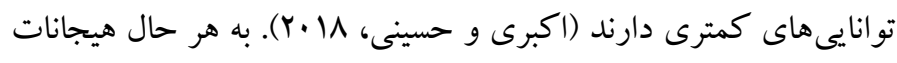

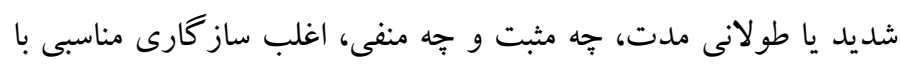
وضعيت سلامتروانى فردى و اجتماعى ندارند و نيازمند تنظيم هستند

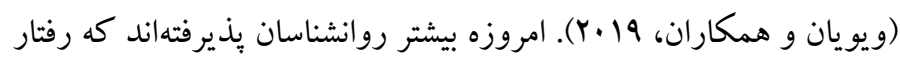
آدمى بيامد ايدها و باورهاى اوست، و نيز اينكه روانشناسى شناختى بيايخاه 
جدول مور كان، مجموعا MAF نفر (مرد و زن) فعال در گروههاى مختلف

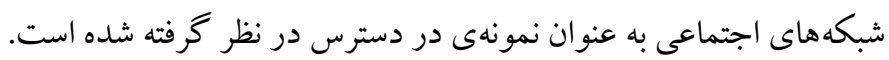

ب) ابزار

براى بررسى انعطافيذيرى شناختى از مقياس انعطافيذيرى شناختى

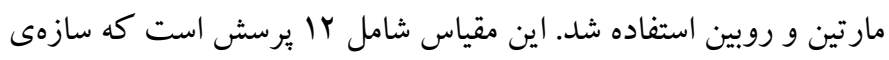
انعطاف بذيرى را در طيف ليكرت از خيلى كم (نمره () تا خيلى زياد (نمره ه) مىسنجد (مارتين و رو بين، (1990). براى بررسى خودنظم جويى هيجان

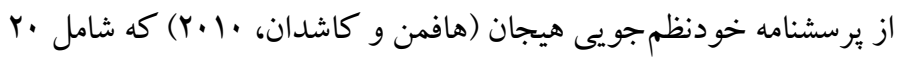
وبرس در طيف ليكرت است بهره گرفتيم؛ و براى بررسى تمايلات

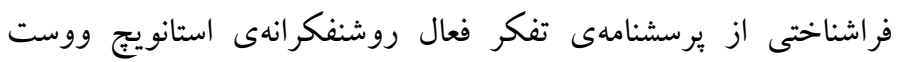

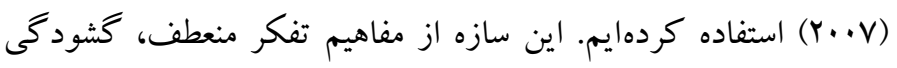
ذهنى و بررسى عقايد و تفكرات خلاف واقع تشكيل شده است. اين

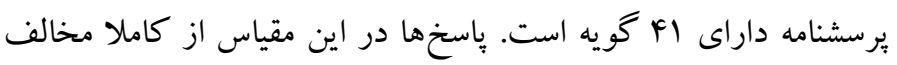

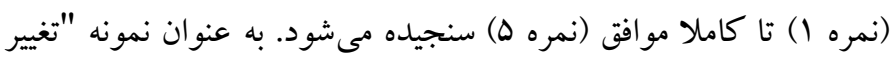
عقيده نشان ضعف است" يكى از گويهها است. اين برسشنامه توسط جو كار و رحيمى به فارسى بر گردانده شده و يايايى و روايى آن مورد تأييد قرار گرفته است (جو كار و رحيمى، بوسمار).

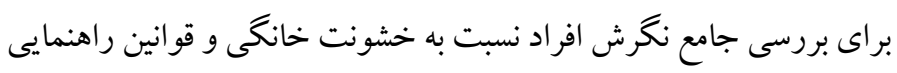

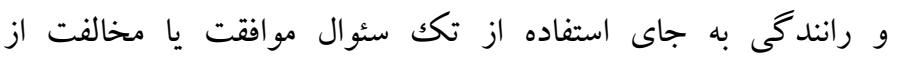

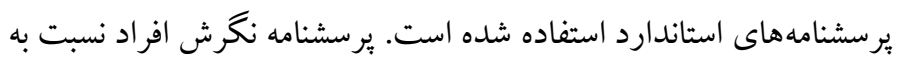

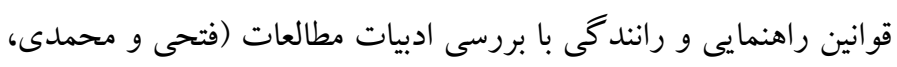

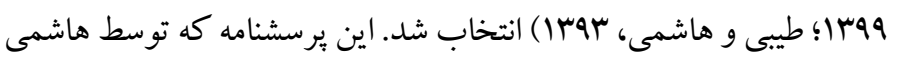

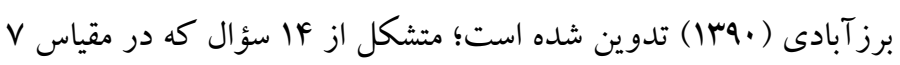

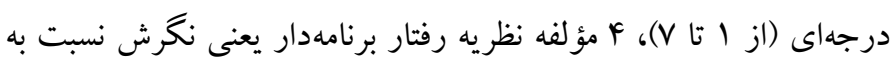

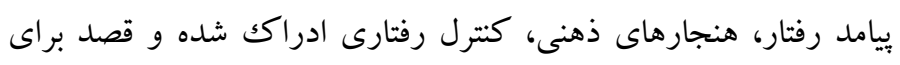

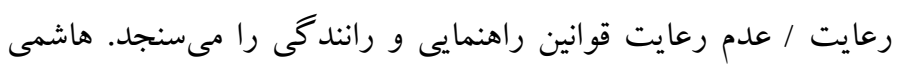

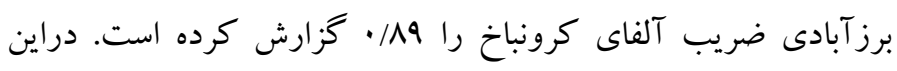
يثزوهش براى بررسى روايى محتو ايى برسشنامه از نظر خبر گان استفاده شد،

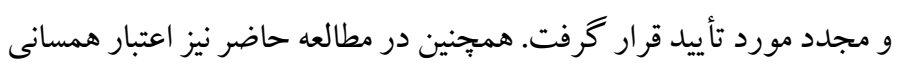

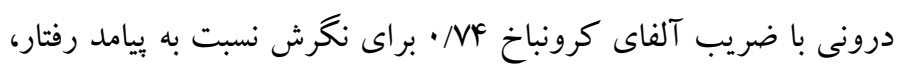

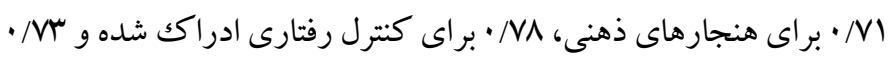

بايد به نخرش به وجود آمده هِت وبست بزنيم تا به حالت اول باز گشت

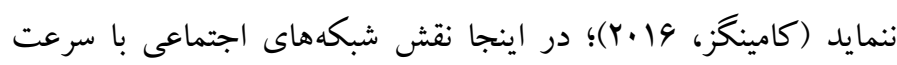
بخشيدن به يايدار كردن نخرش ها اهميت ويزّهاى دارد (بادله و همكاران،

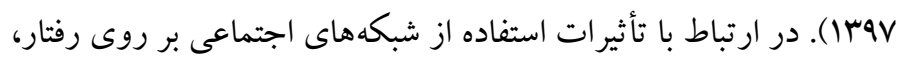

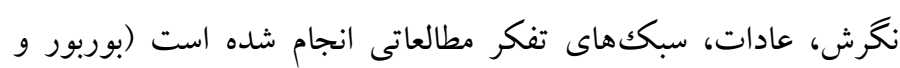

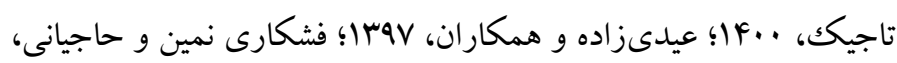

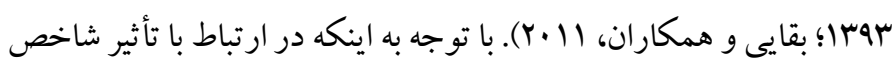
هاى شناختى بر روى تغير نخرش در شبكههاى اجتماعى مطالعهاى مستقيم

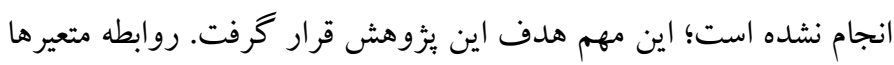

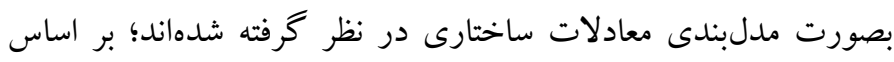

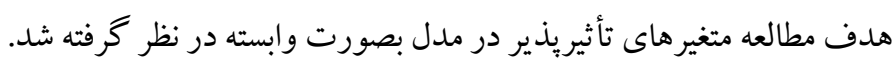

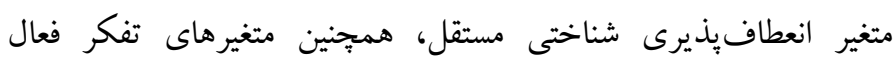

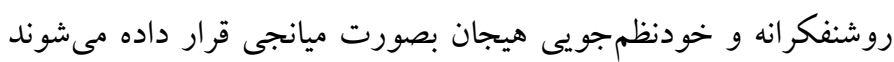

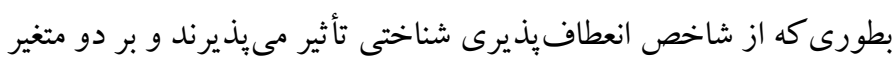

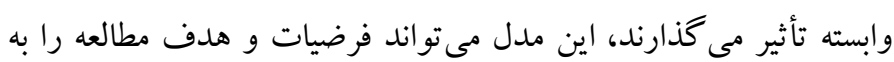
خوبى بوشش دهد. مدل مفهومى در شكل (1) آمده است.

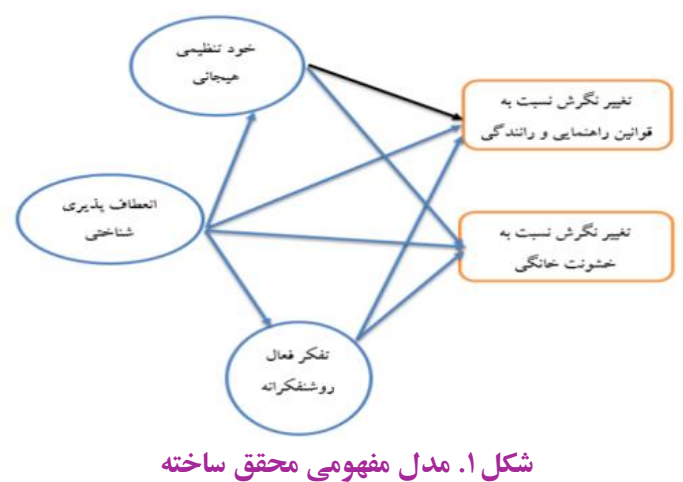

روش

الف) طرح يزوهش و شر كت كنندكان: روش تحقيق حاضر به لحاظ

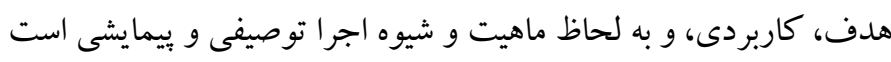

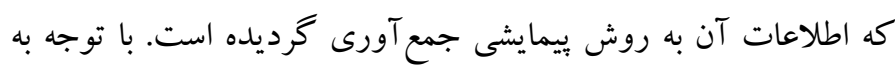
موضوع يزوهش، كه به بررسى رابطهى ميان متغيرها مى يردازد، تحقيق از

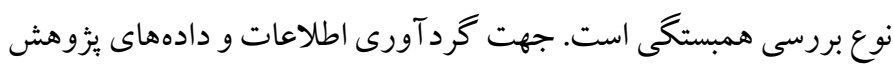
از روشهاى كتابخانهاى و ييمايش استفاده شده است. بدليل نامحدود بودئ بودن

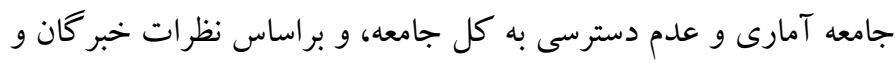


انتخاب شر كت كنند كان مطرح شد. در نهايت، بِ از بايان يافتن مباحث،

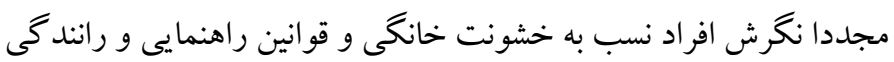

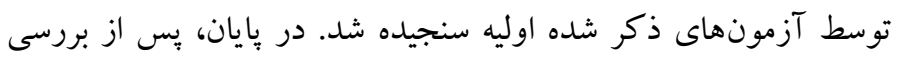

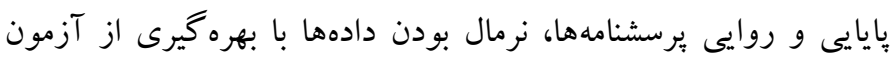

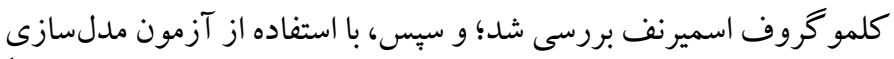

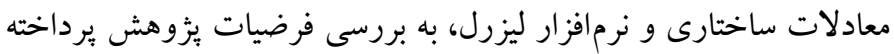

يافته ها يافتهاى توصيفى بيشترين فراوانى معادل .9 درصد مربوط به مردان است. متوسط سنى حاضران در يُزوهش برابر با

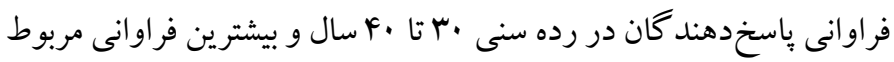
به رده تحصيلى ليسانس و كمتر بود. سطح تحصيلات

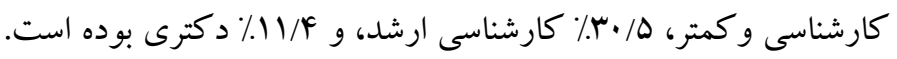
يس از انجام آزمون كلمو گروف اسميرنوف روى يافتهاى استنباطى در اين مطالعه و تأييد نرمال بودن توزيع دادهها، به مدلسازى معادلات ساختارى با نرمافزار ليزرل يرداخته شد، كه نتايج آن در ادامه ارائه مى گرددد.

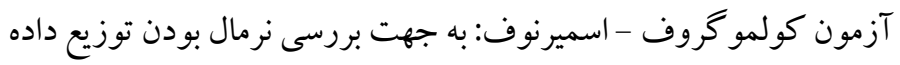

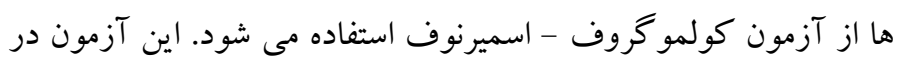
حالت تكك نمونهاى به مقايسه تابع توزيع تجمعى مشاهده شده با تابع توزيع

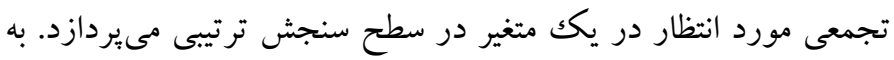

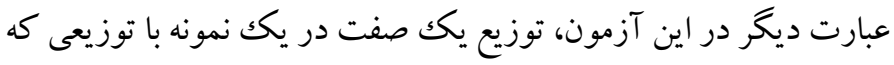
براى آن جامعه مفروض است را مورد مقايسه قرار مى دهد. در تفسير نتايج آزمون، جنانجه مقدار سطح معنىدارى (sig) از سطح احتمال خطا

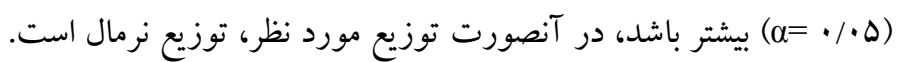

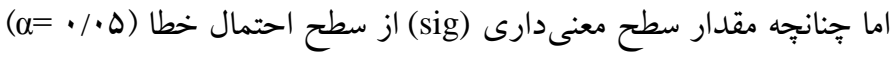
كوجّكتر باشد آنگاه توزيع فوق نرمال نخو اهد بود.
براى قصد انجام رفتار بدست آمد. براى بررسى نخرش افراد نسبت به

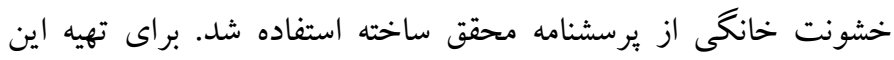

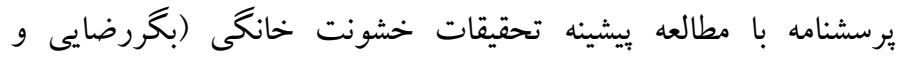

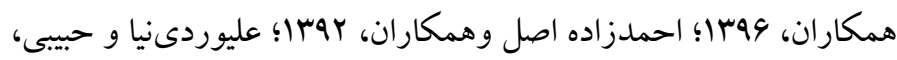

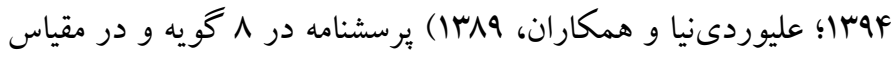
ليكرت تنظيم شده است. اين برسشنامه داراى سه بعد تسلط بر زنان، توجيه

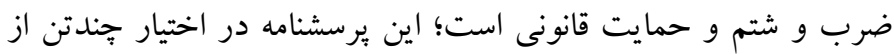

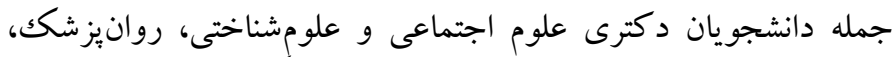

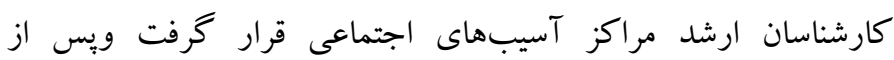
جمع آورى نظرات آنها و انجام تطابق معنايى با نمونهاى مشابه و

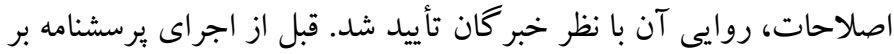

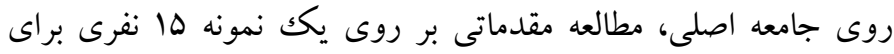

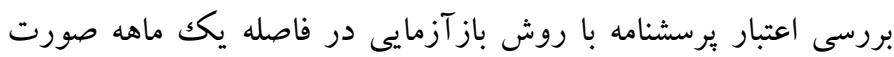

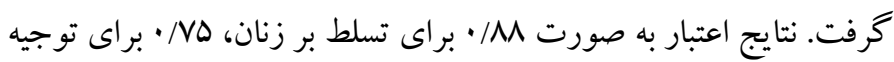
ضرب و شتم و 91/، • براى حمايت قانونى بدست آمد. افراد نمونه از طريق دعوتنامهى رسمى برخط به شركت در يزوهش

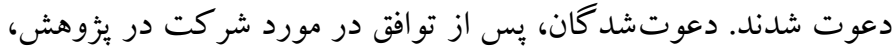

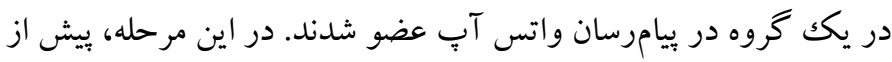

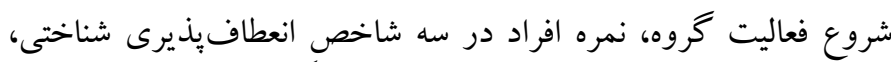

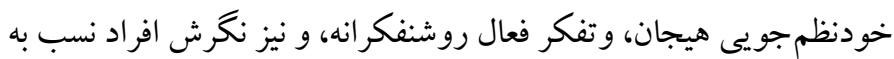

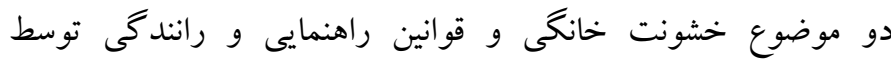

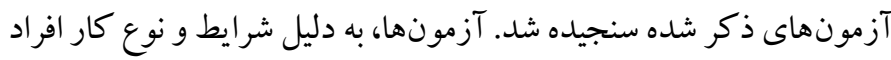

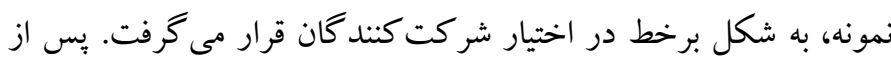

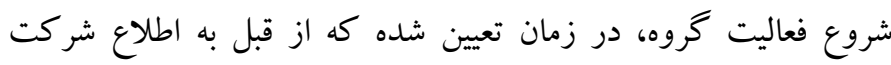

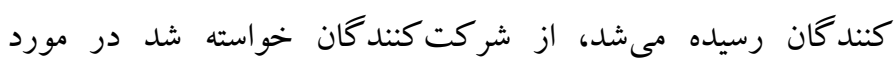
موضوعات مختلف از جمله دو موضوع اصلى اين يزولهش در جند جلسه

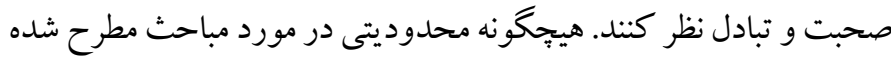
وجود نداشت و هر فردى مى توانست آزادانه نظرات خود را مطرح كند.

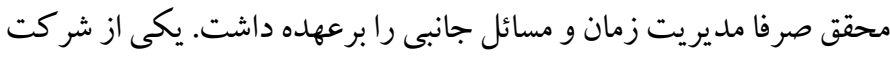

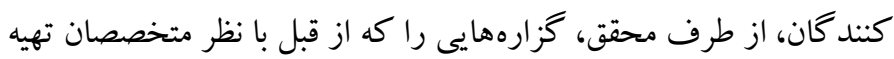
شده بودند، صرفا جهت جريان بحث به تناوب بيان مىكرد. براى

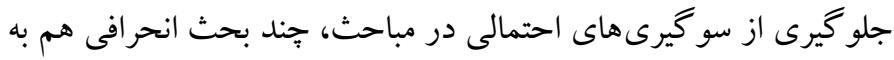


جدول ا. بررسى نرمال بودن توزيع داده ها با آزمون كولموتروف - اسميرنوف

\begin{tabular}{|c|c|c|c|c|}
\hline نتيجه & سطح احتمال خطا & Sig & مقدار آماره & \\
\hline 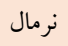 & .1 .0 & $\cdot / r F$. & $1 / Y I F$ & خودنظمجويى هيجان \\
\hline 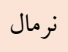 & $.1 . \Delta$ & $\cdot /$ IV & $1 / 411$ & انعطاف يذيرى شناختى \\
\hline 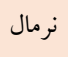 & $\cdot / \cdot \Delta$ & $\cdot / r \cdot r$ & $1 / V \cdot r$ & تفكر فعال روشنفكرانه \\
\hline 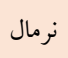 & $\cdot / \cdot \Delta$ & $\cdot / 19$ & $1 / r \Delta 9$ & تغيير نخرش افراد نسبت به قوانين راهنمايى و رانندگى \\
\hline 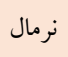 & $\cdot / \cdot \Delta$ & $\cdot / F Y \Lambda$ & $1 / Y \wedge 1$ & تغيير نغرش افراد نسبت به خشونت خانگى \\
\hline
\end{tabular}

توزيع اين متغيرها نرمال است. بنابراين مىتوان از آمارههاى پارامتريك في براى آزمون فرضيههاى تحقيق استفاده نمود.

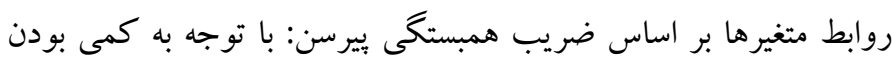

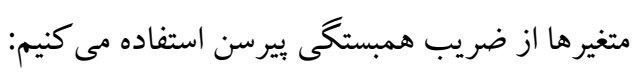

\begin{tabular}{|c|c|c|c|c|}
\hline \multicolumn{5}{|c|}{$=0$} \\
\hline Sig & مقدار & Sig & مقدار & متغيرها \\
\hline$\% \cdots$ & .1099 & $\cdot \cdots$ & $\cdot / v \cdot 1$ & خودنظمجويى هيجان \\
\hline$\bullet \cdots$ &.$/ 011$ & $\% \cdots$ &.$/ 9 V \Delta$ & انعطافيذيرى شناختى \\
\hline$\cdot / \ldots$ & . paft &.$/ \cdots$ & $\cdot / \Delta \wedge 9$ & تفكر فعال روشنفكرانه \\
\hline
\end{tabular}

نمودار شكل (Y) مدل معادلات ساختارى يثوهش را در حالت تخمين

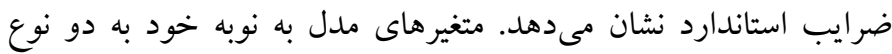

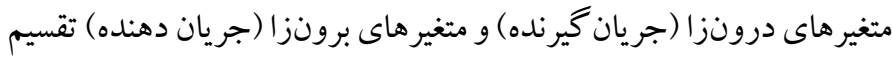
مىشوند. هر متغير در سيستم مدل معادلات ساختارى مى تو اند هم به عنوان

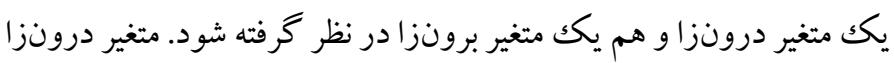
متغيرى است كه از جانب ساير متغيرهاى موجود در مدل تأثير مى بذيرد.

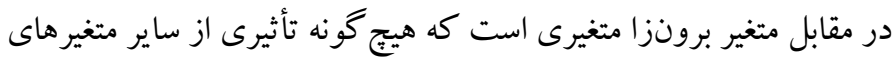

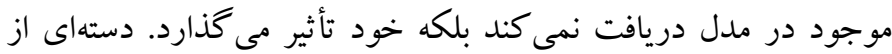

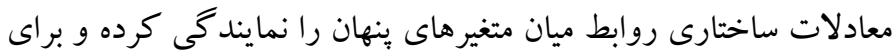

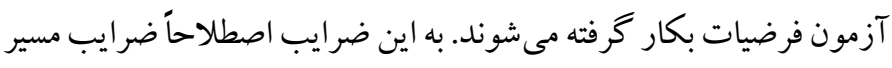

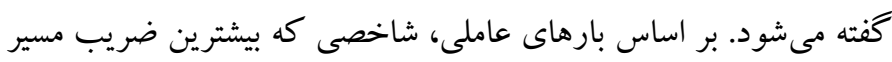

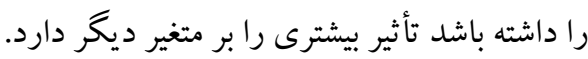

در جدول ا با توجه به مقدار آماره اسميرنوف كلمو گروف حاصل شده همجنين مقدار سطح معنى دارى مى توان استنباط نمود كه توزيع مورد انتظار

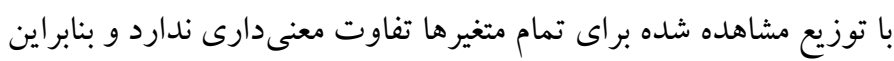
با توجه به مقدار آماره محاسبه شده و سطح خطاى مشاهده شده كمتر از

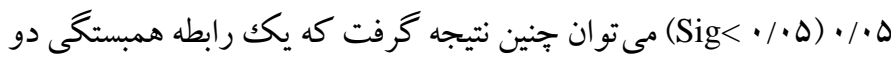
سويه با حداقل سطح اطمينان هذ٪ برقرار است.

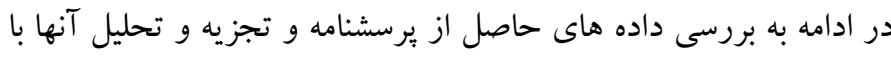

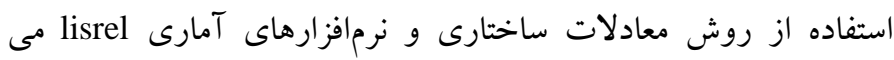
يردازيم، نتايج حاصل بصورت خلاصه و به همراه جدول و نمودار و تحليل ارائه مى شود بطورى كه اين نتايج در راستاى نتايج به دست آمده با نرمافزار

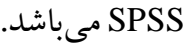
آزمون فرضيه ها با استفاده از روابط ساختاريافته خطى: آزمون فرضيهها با

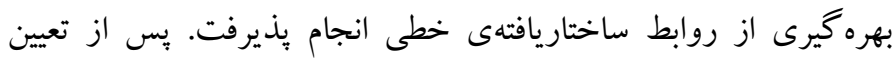
مدلهاى اندازهيرى، به منظور ارزيابى مدل مفهومى تحقيق و همجينين

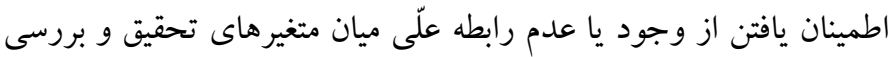
تناسب دادههاى مشاهده شده با مدل مفهومى تحقيق، فرضيههاى تحقيق با

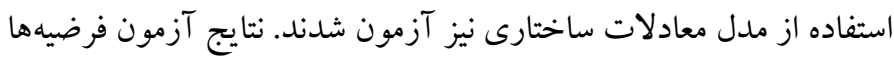

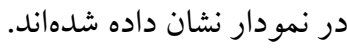


متغير ينهان خود بالاى 1/99 است. لذا مى توان همسويى سؤالات برسشنامه

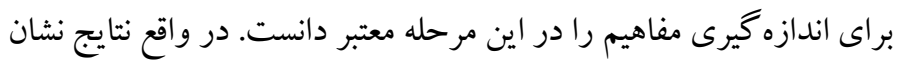

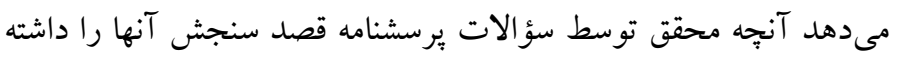

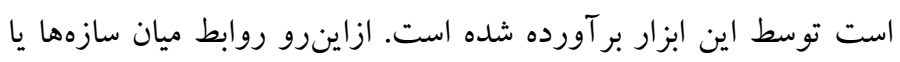
متغيرهاى ينهان قابل استناد است. براى آنكه نشان دهيم اين مقادير به دست آنت

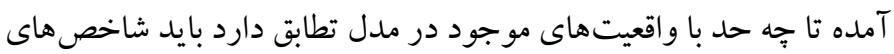

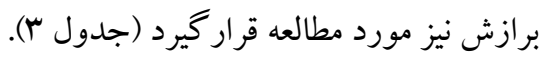

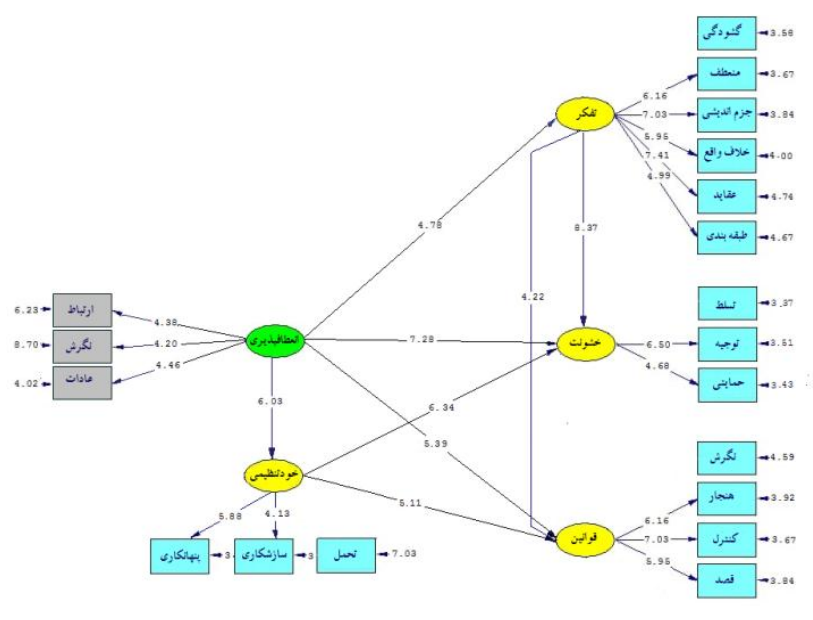

Ch1-square $=34.69$, df $=17, P-v a 1 u=0.00001$, Rusen $=0.077$

شكل ". سنجش مدل كلى و نتايج فرضيه ها در حالت معنىدارى

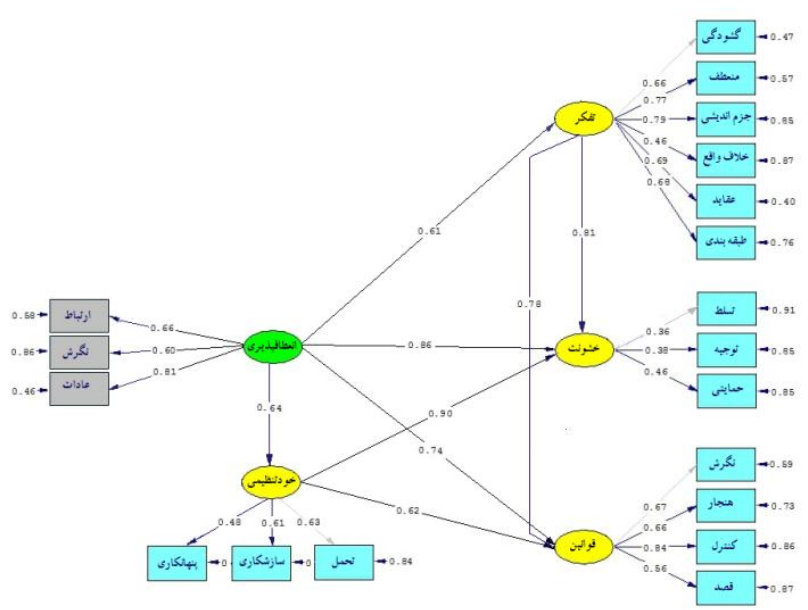

Chi-square $=34,69, \mathrm{df}=17, \mathrm{P}-\mathrm{value}=0.00001$, RusEA $=0.077$

شكل r. سنجش مدل كلى و نتايج فرضيهها در حالت استاندارد

نمودار شكل (r) مدل معادلات ساختارى يُزوهش را در حالت معنادارى ضرايب تى و ليو نشان مىدهد. اين مدل در واقع تمامى معادلات

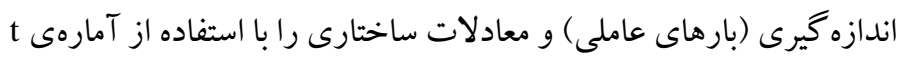
مى آزمايد. بر طبق اين مدل تمامى ضرايب مسير و بارهاى عاملى در حالى حالت

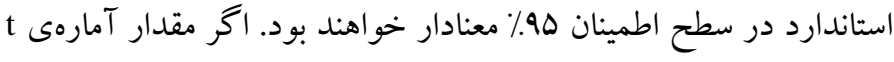

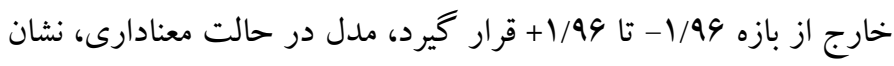
مىدهد كه تمامى بارهاى عاملى در سطح اطمينان هذ\% معنادار هستند.

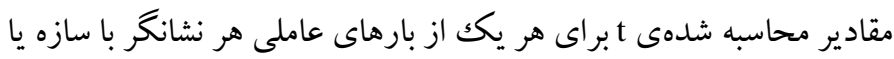

جدول ". تفسير و تعبير مدل معادلات ساختارى

\begin{tabular}{|c|c|c|}
\hline 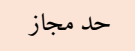 & بر آوردهاى مدل اصلى & نام شاخص \\
\hline 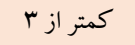 & $r / \cdot F$ & ( كاى دو بر درجهى آزادى) \\
\hline 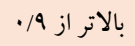 & . /9r & GFI \\
\hline كمتر از 9./. - از & $\cdot / \cdot v$ & RMSEA (ريشه ميانگين مربعات خطاى برآورد) \\
\hline 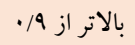 &.$/ 99$ & CFI (برازندگى تعديل يافته) \\
\hline 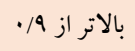 &.$/ 91$ & NFI \\
\hline 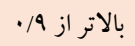 & . /9r & NNFI (برازندگى نرم نشده) \\
\hline 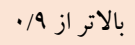 &.$/ 90$ & IFI (برازندگى فزاينده) \\
\hline
\end{tabular}

اندازهاى از مقدار نسبى واريانسها و كواريانسها مىباشد كه توسط مدل تبيين مىشود. اين معيار بين صفر تا يكك متغير است، كه هرجه به عدد يكك نزديكتر باشد نيكويى برازش مدل با دادهاى مشاهده شده بيشتر است.

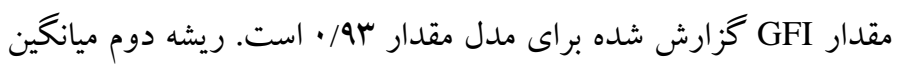

به طور كلى، در كار با برنامه ليزرل، هر يك از شاخصهاى بدست آمده

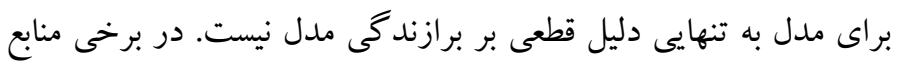

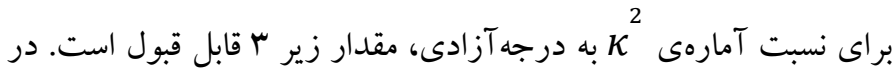

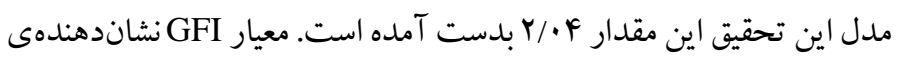


است؛ كه در اين يُوهش براى مدل تحقيق برابر با VV•٪ بر آورد شده

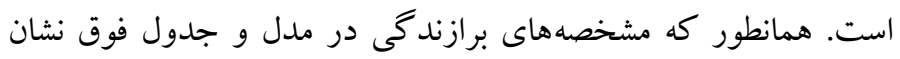
مىدهد، دادههاى اين بزوهش برازش مناسبى با ساختار عاملى و زيربناى

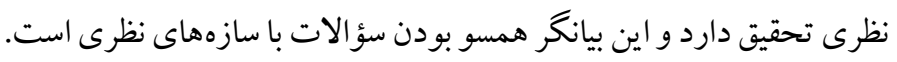

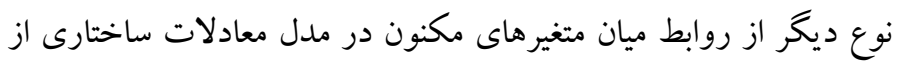

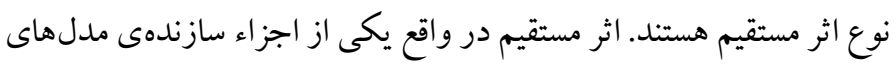
معادلات ساختارى است و رابطه جهت دارى را ميان دو متغير نشان مىدهد. اين نوع اثر در واقع بيانگر تأثير خطى علّى فرض شدهى يكى يك متغير بر متغير

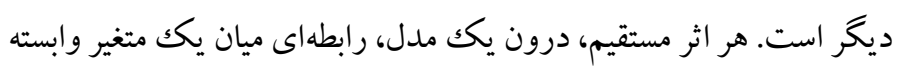

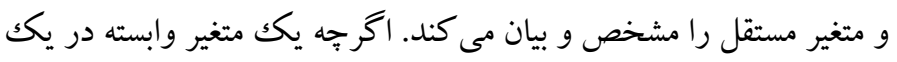

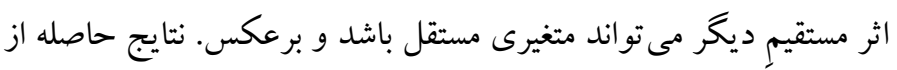
اين روش درجدول أبه قرار زير است:.
مجذور بِ ماندها، تفاوت ميان عناصر ماتريس مشاهده شده در گروه نمونه و عناصر ماتريسهاى بر آورد يا بيشبينى شده با فرض درست بودن مدل

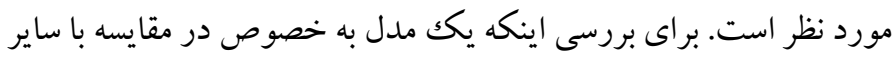

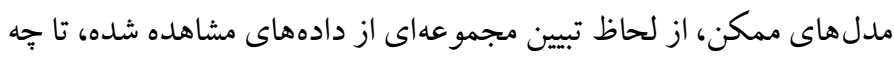

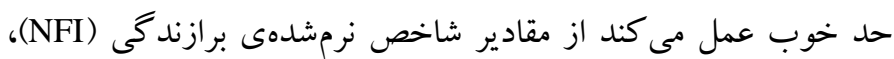

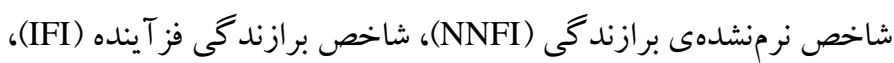
و شاخص برازندگى تطبيقى (CFI) استفاده شده است. مقادير بالاى 9 /.

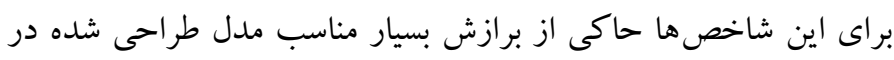

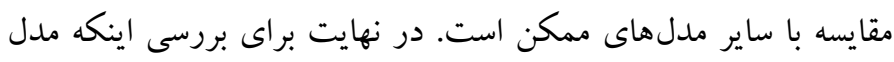

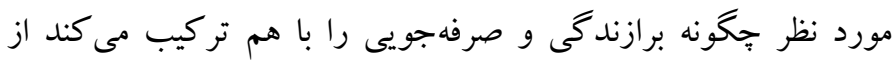

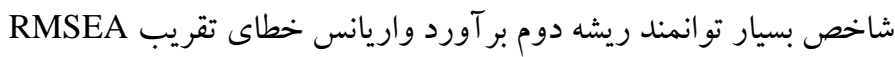
استفاده شده است. شاخص RMSEA ريشه ميانگين مجذورات تقريب روني

جدول ع. ضرايب مسير، آماره t و نتيجه فرضيات تحقيق

\begin{tabular}{|c|c|c|c|c|c|}
\hline نتيجه فرضيه محقق & 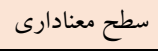 & ضريب تعيين & t & 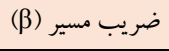 & 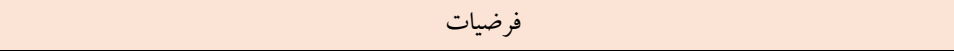 \\
\hline تأييد مىشود & $<\cdot / \cdot \Delta$ & \multirow{8}{*}{$\cdot /$ V^ } & $\mathrm{V} / \mathrm{TA}$ & $\cdot / \wedge 9$ & 1. انعطاف يذيرى شناختى بر تغيير نخرش نسبت به خشونت خانخى عليه زنان داراى تأثيرى معنادار است. \\
\hline تأيبد مىشود & $<\cdot / \cdot \Delta$ & & $\Lambda / Y V$ & $\cdot / \wedge \mid$ & r. تفكر فعال روشنفكرانه بر تغيير نخرش نسبت به خشونت خانگى عليه زنان داراى تأثيرى معنادار است. \\
\hline تأييد مىشود & $<\cdot / \cdot \Delta$ & & $9 / M F$ & $\cdot / 9$. & r. خودنظم جويى هيجان بر تغيير نخحرش نسبت به خشونت خانگى عليه زنان داراى تأثيرى معنادار است. \\
\hline تأييد مىشود & $<\cdot / \cdot \Delta$ & & $\Delta / r q$ & $\cdot / \mathrm{V}^{\mathrm{F}}$ & f. انعطاف يذيرى شناختى بر تغيير نخرش نسبت به قوانين راهنمايى و رانندگى داراى تأثيرى معنادار است. \\
\hline تأييد مىشود & $<\cdot / \cdot \Delta$ & & F/Yr & $\cdot / \mathrm{v} \Lambda$ & ه. تفكر فعال روشنفكر انه بر تغيير نحرش نسبت به قوانين راهنمايى و رانندگى داراى تأثيرى معنادار است. \\
\hline تأييد مىشود & $<\cdot / \cdot \Delta$ & & $\Delta / 11$ & $\cdot 194$ & 9. خودنظم جويى هيجان بر تغيير نخرش نسبت به قوانين راهنمايى و رانندگى داراى تأثيرى معنادار است. \\
\hline تأييد مىشود & $<\cdot / \cdot \Delta$ & & 91.4 & $\cdot 194$ & V. انعطاف يذيرى شناختى بر خود نظم جويى هيجان داراى تأثيرى معنادار است. \\
\hline تأييد مىشود & $<\cdot / \cdot \Delta$ & & $r / v \wedge$ & .191 & 1 انعطاف يذيرى شناختى بر تفكر فعال روشنفكر انه داراى تأثيرى معنادار است. \\
\hline
\end{tabular}

بذيرفته مىشود. مقدار ضريب تعيين (R Square) نشان مىدهد كه عوامل

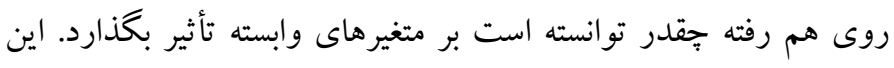

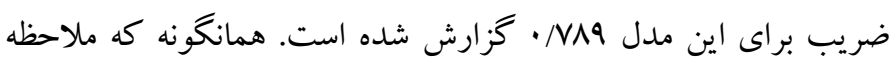

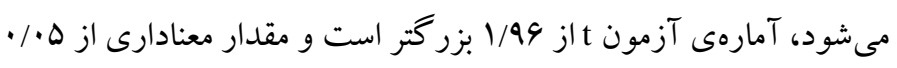

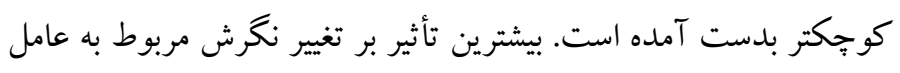

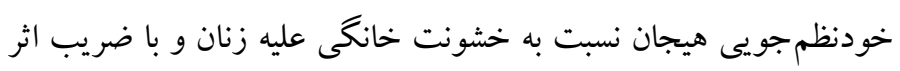
(9. - 19.

\section{بحث و نتيجه گيرى}

يافته هاى اين مطالعه نشان داد كه افراد با انعطاف يذيرى برى شناختى بالاتر در

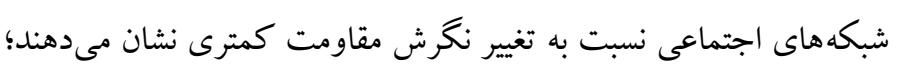

همانگگنه كه از نتايج مشخص است انعطاف يذيرى شناختى مستقيما روى تغيير نغرش نسبت به خشونت خانگى و قوانين رانندگى تأثير معنادار دارد.

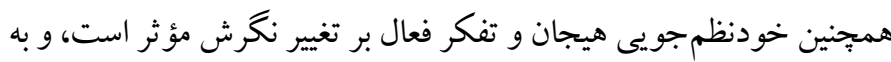

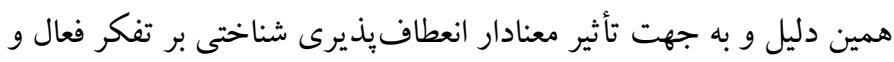

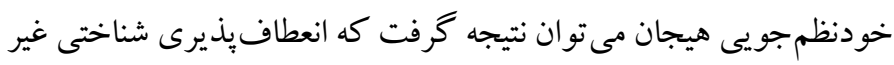
مستقيم نيز بوسيله ميانجى گرى اين دو شاخص (تفكر فعال و خون خودنظم

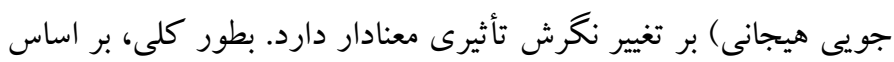
t نتايج بدست آمده، تأثير متغيرها داراى مقدار t قابل قبولى است. مقدار

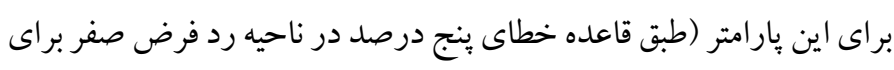

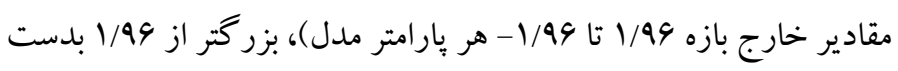
آمده است. لذا مى توان بيان نمود كه فرضيههاى فوق با هه درصد باره اطمينان 
روز مى كنند و بسيارى از اطلاعات نخران كننده را ناديده مى گيرند. و از

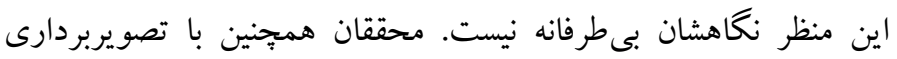

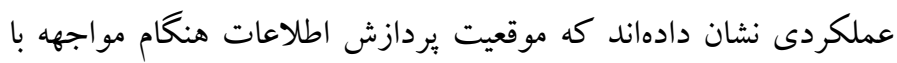

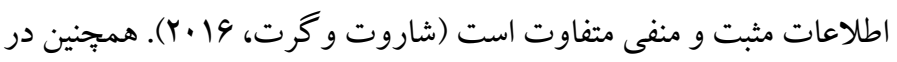
يزؤهش شهامتىنزاد بر روى رابطه اضطر اب سلامت و تنظيم هيجان با شايعه در شبكه اجتماعى در زمان كرونا، گزارش شده است؛ كه ميان تنظيم هيجان

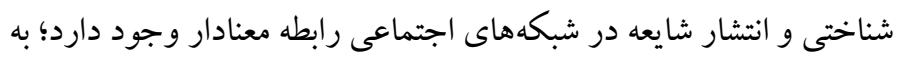

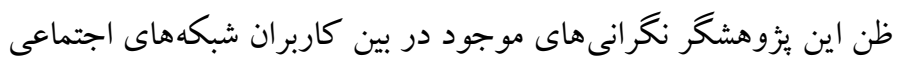

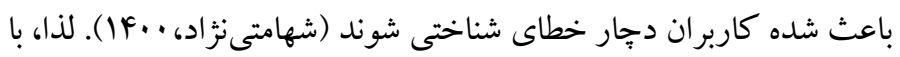
توجه به خروجى هاى مدل و مباحث مطرح شده، تنظيم هيجان (كه توانايى

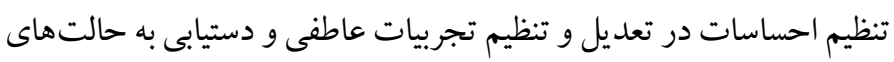

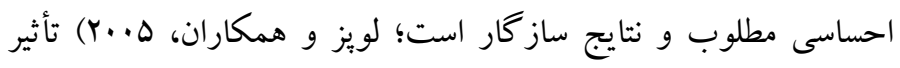

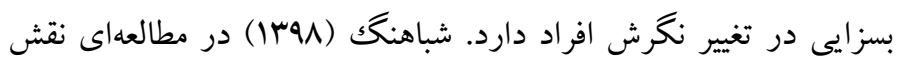
انعطاف يذيرى شناختى و مشكلات تنظيم هيجانى در نخرش دانشجويان به نهريه

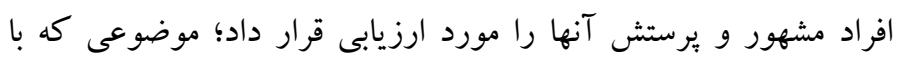

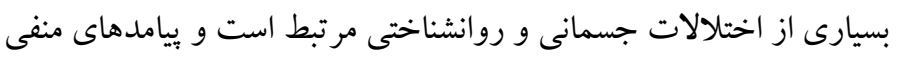

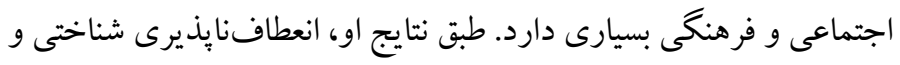

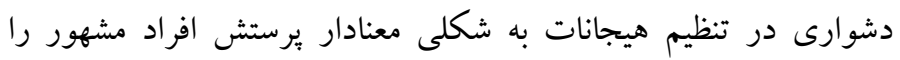
ييشينى مى كنند. با اين حال، بيرو يافتهاى همان يُزوهش، با اعمال

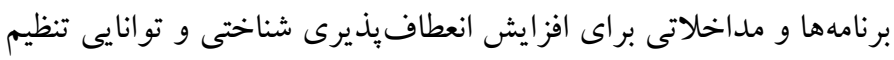

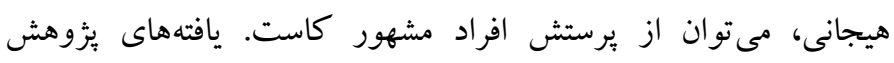

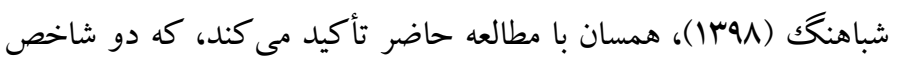
انعطاف بذيرى شناختى و خودتنظيمى هيجانى با تغيير نخرش افراد مرتبط هستند. آخرين متغير مورد بررسى، مقياس تفكر فعال روشنفكرانه است.

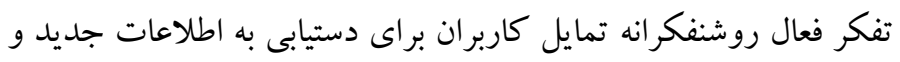
اتخاذ يكك ذهنيت روش مند و متفكر انه است. جنين تمايلى مى تواند در روند

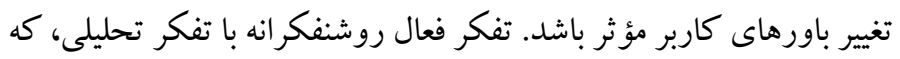

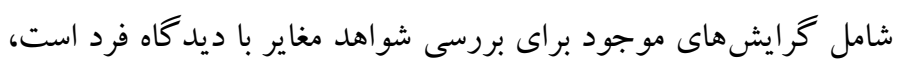

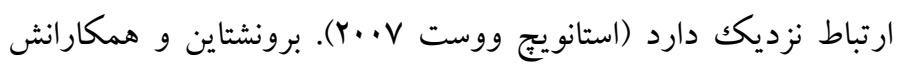

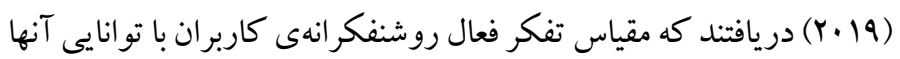

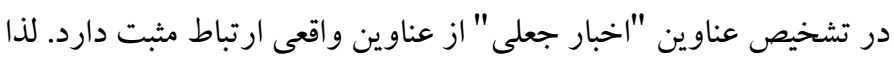
تفكر فعال روشنفكرانه با عملكرد منطقى ارتباط مستقيم دارد. همجنين در
انعطافيذيرى شناختى را توانايى تغيير افكار و اعمال در پياسخ به خواستهاى ناشى از شرايط و مشكلات تعريف كردهاند (يزبرناردو و

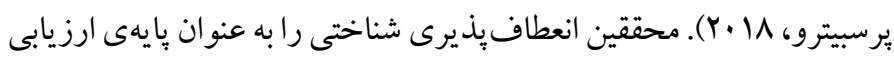

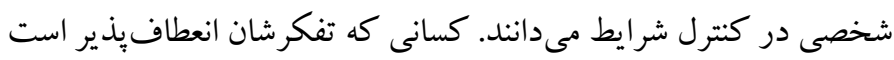

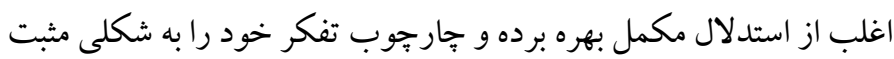

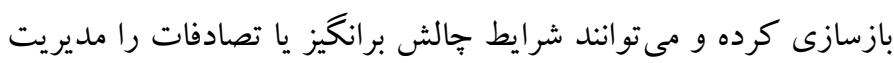

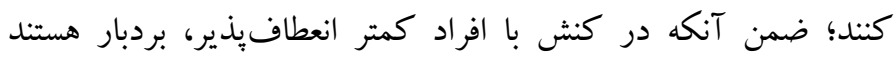

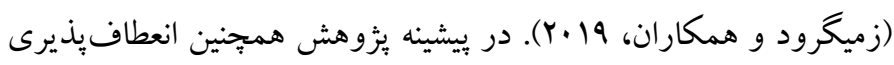

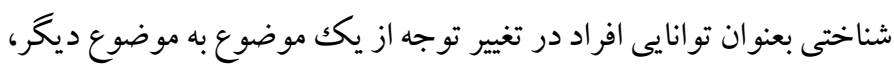

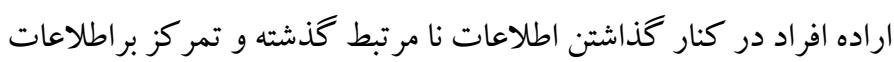

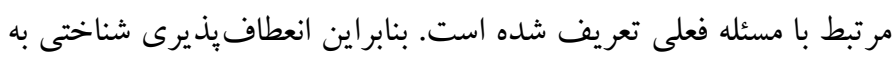

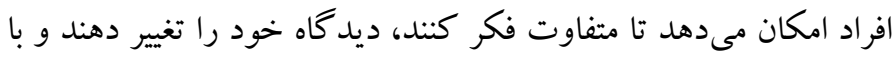

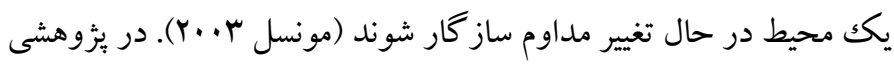

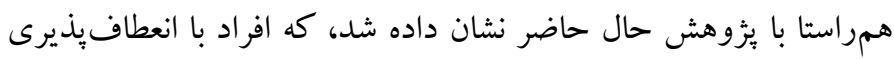

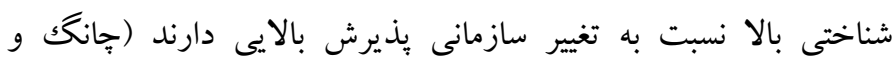

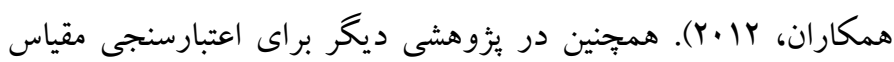

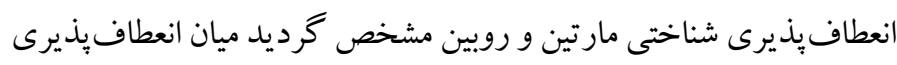

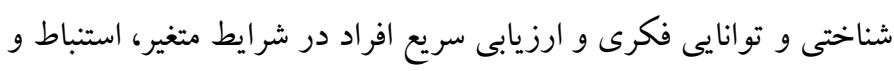

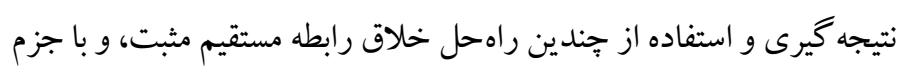

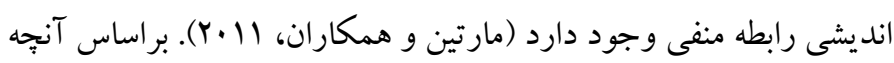

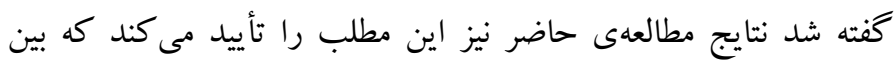

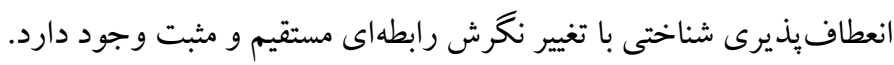

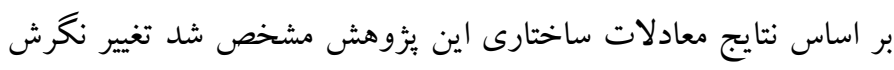

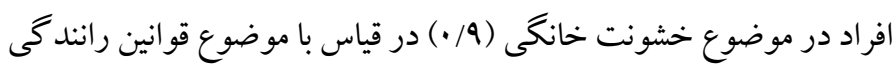

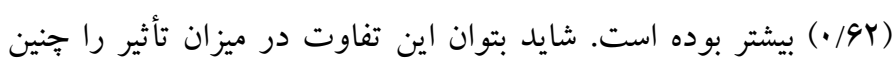

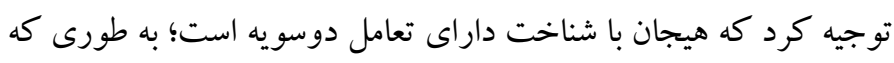

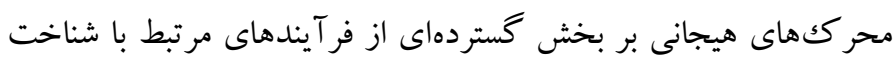

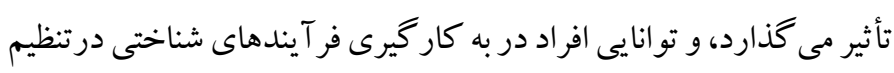

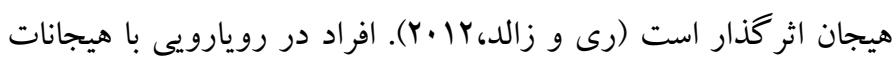

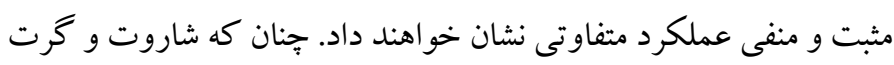
در مطالعهى خود دريافتند كه افراد بيشتر تحت تأثير اطلاعات با احساسات

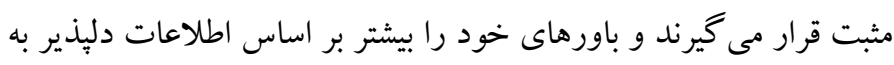


مطالعات بيشترى در زمينه شناخت عو امل شناختى مؤثر در شكل گيرى نغرش كاربران شبكههاى اجتماعى انجام دهند و ييرامون تقويت و كنترل

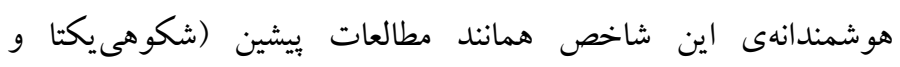

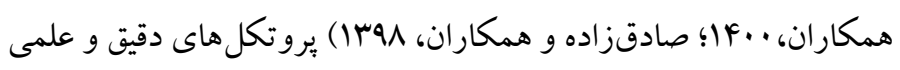

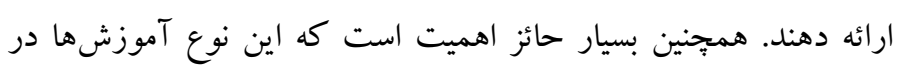
مدارس و در ميان خانو ادهها نهادينه شود.

\section{ملاحضات اخلاقى}

يبروى از اصـول اخلاق ئوهش: إين مقاله بركرفته از بخشسى از رسـاله دكترى

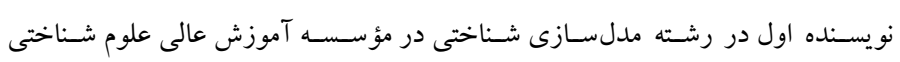

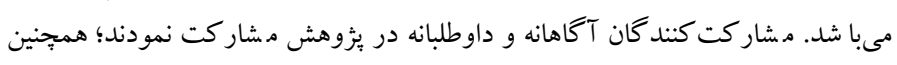

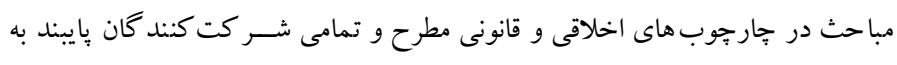

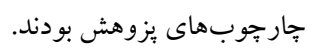

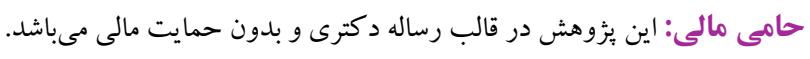

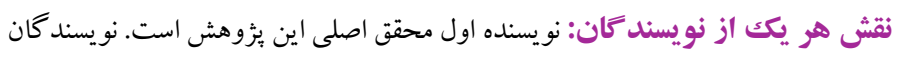

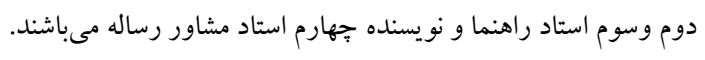
تضاد منافع: نويسند كان هيج تضاد منافعى در رابطه با اين يزوهش اعلام نمىنمايند.

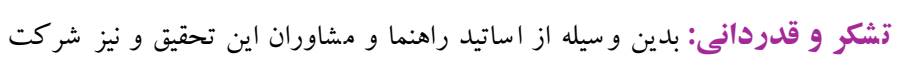

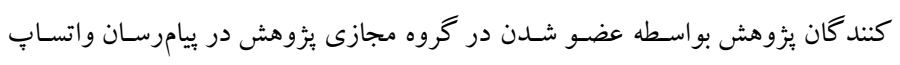
كمال تشكر را دارم.
مطالعهاى ديخر نشان داده شد كه ويزگى شخصيتى گشودگى (باز بودن

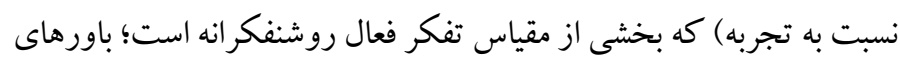

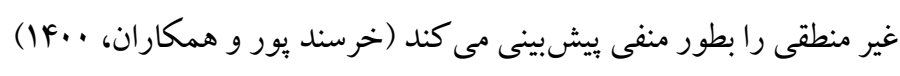

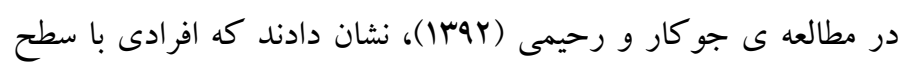
شناخت بالا، با جمع آورى اطلاعات هر جه بيشتر و همجنين تفكر در مورد

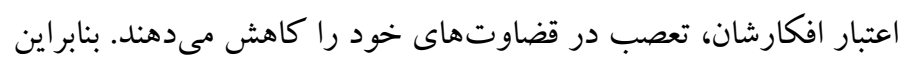

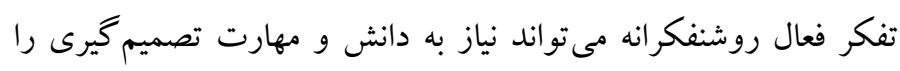

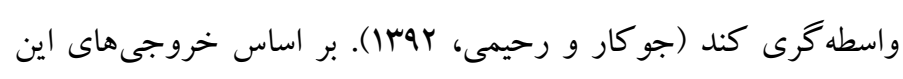

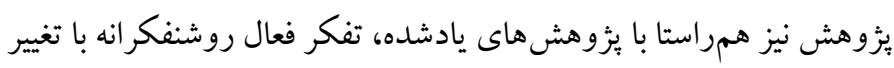

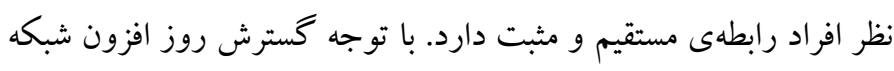

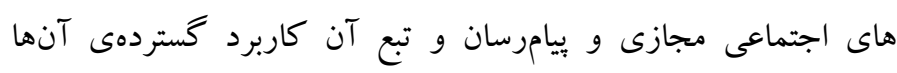

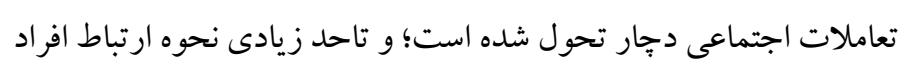
را سمت و سو داده است. جايكاه شبكه هاى اجتماعى را در شكل دهدى افكار

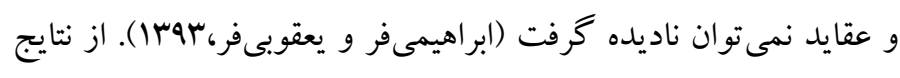
مطالعهى حاضر مىتوان دريافت كه شبكه هاى اجتماعى تا جه ميزان

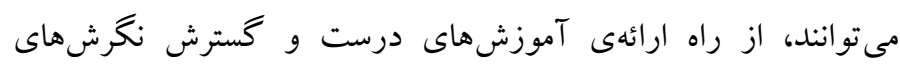

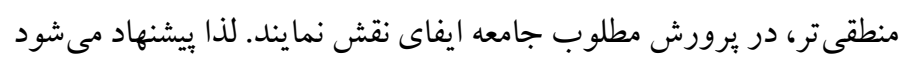

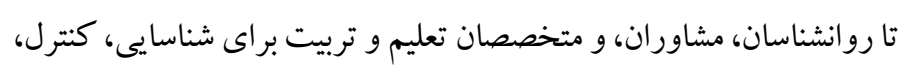

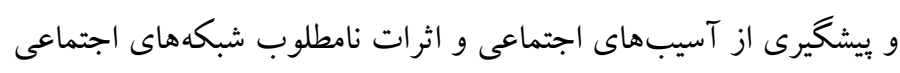




\section{References}

Ahmadzad Asl, m., Ddavoudi, F., Zarei, N., Mohammadsadeghi, H., Khademolreza, n., Rasoulian, M. (2013). Design and evaluation of an inventory to examine knowledge and attitude about domestic violence against women. Iranian journal of psychiatry and clinical psychology, 19(1 (72)), 43-53. (Persian) [Link]

Akbari, M., Hossaini, S. M. (2018). The relationship of spiritual health with quality of life, mental health, and burnout: The mediating role of emotional regulation. Iranian journal of psychiatry, 13(1), 22. (Persain)[Link]

Aliverdinia, A., Habibi, M. (2016). The Study of University Male Students Attitude toward Violence against Woman in Family Context: An Empirical Test of Akers Social learning Theory. Strategic Rssearch on Social Problems in Iran University of Isfahan, 4(3), 15-38(Persian)[Link]

Aliverdinia,A.,Ryahi, M.,Esfandiari, F. (2010).Explaining the attitudes of female students towards violence against women.An experimental test of social learning perspective. Social Issues of Iran, 1(1),103131. (Persian). [Link]

Badeleh, A., Gholinejad, N., Bigdeli, M. (2018). The relationship between the use of cybernetics and social knowledge, attitude, behavior and social security of students. Quarterly of Order and Security Guards, 11(3 (43)), 135-158. (Persian). [Link]

Baghaei, N., Kimani, Stephe., Freyne, J., Brindal, E., Berkovsky, S., Smith,G. (2011). Engaging Families in Lifestyle Changes Through Social Networking. Int. J. Hum. Comput. Interaction. 27. 971-990. DOI: 10.1080/10447318.2011.555315. [Link]

Bagrezaei, P., Zangani, H., Seifollahi, S. (2017). A metaanalysis of the studies on the violence of husbands against wives in Iran. The Women and Family Cultural Education, 11(38), 71-97. (Persian) [Link]

Bernardo, A. B. I., Presbitero, A. (2018). Cognitive flexibility and cultural intelligence: Exploring the cognitive aspects of effective functioning in culturally diverse contexts. International Journal of Intercultural Relations, 66, 12-21. [Link]

BoorBoor, A., Tajik Esmaeili, S. (2021). Study the relationship between the amount and type of use of virtual social networks With the social identity of women in Tehran. Quarterly Social Psychology Research, 11(41), 137-159. (Persian). [Link]

Bronstein, M. V., Pennycook, G., Bear, A., Rand, D. G., \& Cannon, T. D. (2019). Belief in fake news is associated with delusionality, dogmatism, religious fundamentalism, and reduced analytic thinking. Journal of Applied Research in Memory and Cognition, 8(1), 108-117. [Link]

Carpenter, J., Preotiuc-Pietro, D., Clark, J.L., Flekova, L., Smith, L.K., Kern, M.L., Buffone, A., Ungar, L., Seligman, M. (2018). The impact of actively openminded thinking on social media communication. Judgment and Decision Making, 13, 562-574. [link]

Cummings, S., Bridgman, T., Brown, K. G. (2016). Unfreezing change as three steps: Rethinking Kurt Lewin's legacy for change management. Human Relations, 69(1), 33-60. [Link]

Eydi Zade, R., Ahmadi Blotaki, H. (2018). The relationship between the usage of what's app and telegram social networks and life style social sciences' students in science and research branch. Sociological studies, 11(38), 43-60. (Persian). [Link]

Fathi, A., Mohammadi, F. (2020). The relationship between personality traits and high-risk driving behaviors and attitude to observance of traffic rules in intra-city drivers. Traffic Law Enforcement Research Studies, 2020(32), 83-112. (Persian) [Link]

Graziano, P., Hart, K.C. (2016). Beyond behavior modification: Benefits of social-emotional/selfregulation training for preschoolers with behavior problems. Journal of school psychology, 58, 91111. DOI:10.1016/j.jsp.2016.07.004. [Link]

Khorsandpour T, Rezakhani S, Sharifi H. (2021).The structural pattern of irrational beliefs based on personality traits and self-esteem in students: the mediating role of critical thinking.Journal of Psychological Science, 20 (101),775-786. (Persian) [Link]

Hashemi Borzabadi,H. (2011).The role of executive actions and attitudes in the occurrence of high-risk traffic behaviors.MS Thesis. Ferdosi University of Mashhad, Faculty of Education and Psychology. (Persian). [Link]

Hofmann, S. G., Kashdan, T. B. (2010). The affective style questionnaire development and psychometric properties. Journal of psychopathology and behavioral assessment, 32(2), 255-263. [Link]

Jagnoor, J., Sharma, P., Parveen, S., Cox, K. L., Kallakuri, S. (2020). Knowledge is not enough: barriers and facilitators for reducing road traffic injuries amongst Indian adolescents, a qualitative study. International Journal of Adolescence and Youth, 
25(1),

787-799.

DOI:10.1080/02673843.2020.1746675. [Link]

Jowkar, B., Rahimi, M. (2013). The Effect of Anger and Cognitive Styles on Decision Making Process with the Mediating Role of Metacognitive Dispositions: An integrated Model in Decision Making. Educational Psychology, 9(27), 68-96. (Persian). [Link]

Karimi, K., Ghafari Ghadir, J. (2019). The Model of influencing on public-opinion in Cyberspace with the help of Gamification Capabilities. New Media Studies, 5(17), 137-172. (Persian). [Link]

Kuflik, T., Minkov, E., Nocera, S., Grant-Muller, S., GalTzur, A., Shoor, I. (2017). Automating a framework to extract and analyse transport related social media content: The potential and the challenges. Transportation Research Part C-emerging Technologies, 77, 275-291. DOI:10.1016/J.TRC.2017.02.003. [Link]

Levitan, L. C., Verhulst, B. (2016). Levitan, L. C., Verhulst, B. (2016). Conformity in groups: The effects of others' views on expressed attitudes and attitude change. Political Behavior, 38(2), 277-315. DOI:10.1007/S11109-015-9312-X. [Link]

Martin, M. M., Rubin, R. B. (1995). Anew measure of cognitive flexibility. Psychological Reports, 76,623-626. [Link]

Matthew M. Martin, Sydney M. Staggers, Carolyn M. Anderson (2011) The Relationships Between Cognitive Flexibility with Dogmatism, Intellectual Flexibility, Preference for Consistency, and SelfCompassion, Communication Research Reports, 28:3, 275-280. [Link]

Mohammadbeigi, A., Mohammadsalehi, N., Aligol,M. (2015) Validity and Reliability of the Instruments and Types of MeasurmentS in Health Applied Researches. JRUMS, 13 (12), 1153-1170. (Persian). [Link]

Monsell, S. (2003) Task Switching. Trends in Cognitive Sciences, 7, 134-140. [Link]

Ray RD, Zald DH. (2012) Anatomical insights into the interaction of emotion and cognition in the prefrontal cortex. Neurosci Biobehav Rev; 36(1):479-501.

doi: 10.1016/j.neubiorev.2011.08.005. [Link]

Sadeghzadeh R, Ahadi H, Dortaj F, Manshaee G. (2019) The effectiveness of cognitive - behavioral therapy and metacognition based learning combination on reducing social network dependency. Journal of Psychological Science,18 (78),659-666. (Persian). [link]
Schwarz, Marco A. (2017): The Impact of Social Media On Belief Formation. Collaborative Research Center Transregio 190, Discussion Paper No. 57. [Link]

Seo, S. O., Shim, M. K. (2016). The effect of maternal attitude toward child's emotional expressiveness, young child's attachment stability, and emotional regulation ability on young child's problematic behaviors. Korean Journal of Child Studies, 37(4), 1-15. [Link]

Shabahang, R., Besharat, M., nikoogoftar, M., Bagheri Sheykhangafshe, F. (2019). Role of Cognitive Flexibility and Emotional Regulation Problems in Prediction of Celebrity WorshipamongUniversity Students. Knowledge \& Research in Applied Psychology, 20(1), 13-25. (Persian). [Link]

Shahamatinejad, S. (2021). The Relationship between Health Anxiety and Emotion Regulation with Rumors on Social Networks during the COVID-19 Pandemic. jarcp. 3 (1):38-48. (Persian). [Link]

Sharot, T., \& Garrett, N. (2016). Forming Beliefs: Why Valence Matters. Trends in Cognitive Sciences, 20, 25-33. DOI:10.1016/j.tics.2015.11.002. [Link]

Shekari Namin, S., Hajiyani, E. (2014). A Study on effects of Virtual social networks (Facebook) On Youngsters' Lifestyle. Journal of Cultural Management, 8(26), 63-79. (Persian). [Link]

Shokoohi-Yekta M, Ghasemzadeh S, Matbou Riahi M. (2021).Effects of psycho-social skills training on bus drivers' aggression and cognitive flexibility. Journal of Psychological Science,101(20), 719-727. (Persian). [link]

Stad, F. E., Van Heijningen, C. J., Wiedl, K. H., \& Resing, W. C. (2018). Predicting school achievement: differential effects of dynamic testing measures and cognitive flexibility for math performance. Learning and Individual Differences, 67, 117-125. [Link]

Stanovich, K. E., Toplak, M. E. (2019). The need for intellectual diversity in psychological science: Our own studies of actively open-minded thinking as a case study. Cognition, 187, 156-166. [Link]

Stanovich, K. E., West, R. F. (2007). Natural myside bias is independent of cognitive ability. Thinking \& Reason ing, 13, 225-247. [Link]

Stenhouse, N., Myers, T. A., Vraga, E. K., Kotcher, J. E., Beall, L., Maibach, E. W. (2018). The potential role of actively open-minded thinking in preventing motivated reasoning about controversial science. DOI:10.1016/j.jenvp.2018.06.001. [Link] 
Su, Y.-F., Chung, S.-H., Su, S.-W. (2012). The impact of cognitive flexibility on resistance to organizational change. Social Behavior and Personality: An international journal, 40(5), 735-746. [link]

Tayebi,Z., Chahouni Hashemi, S.M. (2014). Predictors of aberrant driving behavior: Traffic risk perception, attitudes and intention to exceeding the speed limits. Quarterly Social Psychology Research,,4(13),5460. (Persian). [Link]

Vivian, E., Oduor, H., Arceneaux, S. R., Flores, J. A., Vo, A., Madson Madden, B. (2019). A cross-sectional study of perceived stress, mindfulness, emotional self-regulation, and self-care habits in registered nurses at a tertiary care medical center. SAGE Open Nursing, 5:1-15. [Link]

Yazdkhasti,B.,MahmoudMoulai,B. (2009).The role of media in reducing accidents. The first national conference of roadway and railway accident and furtuites. (Persian). [Link]

Yu, Y., Yu, Y., \& Lin, Y. (2020). Anxiety and depression aggravate impulsiveness: the mediating and moderating role of cognitive flexibility. Psychology, health \& medicine, 25(1), 25-36. [Link]

Zmigrod, L., Zmigrod, S., Rentfrow, P. J.,Robbins, T. W. (2019). The psychological roots of intellectual humility: The role of intelligence and cognitive flexibility. Personality and Individual Differences, 141, 200-208. [Link] 